\title{
Efficacy of Triazole-Based Fungicides for Fusarium Head Blight and Deoxynivalenol Control in Wheat: A Multivariate Meta-Analysis
}

\author{
P. A. Paul, P. E. Lipps, D. E. Hershman, M. P. McMullen, M. A. Draper, and L. V. Madden
}

First, second, and sixth authors: Department of Plant Pathology, The Ohio State University, Ohio Agricultural Research and Development Center, Wooster 44691; third author: Department of Plant Pathology, University of Kentucky, Princeton 42445; fourth author: Department of Plant Pathology, North Dakota State University, Fargo; and fifth author: USDA-CSREES, Washington, DC 20250.

Accepted for publication 30 April 2008.

\begin{abstract}
Paul, P. A., Lipps, P. E., Hershman, D. E., McMullen, M. P., Draper, M. A., and Madden, L. V. 2008. Efficacy of triazole-based fungicides for Fusarium head blight and deoxynivalenol control in wheat: A multivariate meta-analysis. Phytopathology 98:999-1011.

The effects of propiconazole, prothioconazole, tebuconazole, metconazole, and prothioconazole+tebuconazole (as a tank mix or a formulated premix) on the control of Fusarium head blight index (IND; field or plotlevel disease severity) and deoxynivalenol (DON) in wheat were determined. A multivariate random-effects meta-analytical model was fitted to the log-transformed treatment means from over 100 uniform fungicide studies across 11 years and 14 states, and the mean log ratio (relative to the untreated check or tebuconazole mean) was determined as the overall effect size for quantifying fungicide efficacy. Mean log ratios were then transformed to estimate mean percent reduction in IND and DON relative to the untreated check (percent control: $\bar{C}_{I N D}$ and $\bar{C}_{D O N}$ ) and relative to tebuconazole. All fungicides led to a significant reduction in IND and DON $(P<0.001)$, although there was substantial between-study variabil-

DON, metconazole was the most effective treatment, with a $\bar{C}_{D O N}$ of $45 \%$; prothioconazole+tebuconazole and prothioconazole showed similar efficacy, with $\bar{C}_{D O N}$ values of 42 and $43 \%$, respectively; tebuconazole and propiconazole were the least effective, with $\bar{C}_{D O N}$ values of 23 and $12 \%$, respectively. All fungicides, with the exception of propiconazole, were significantly more effective than tebuconazole for control of both IND and DON $(P<0.001)$. Relative to tebuconazole, prothioconazole, metconazole, and tebuconzole+prothioconzole reduced disease index a further 14 to $20 \%$ and DON a further 25 to $29 \%$. In general, fungicide efficacy was significantly higher for spring wheat than for soft winter wheat studies; depending on the fungicide, the difference in percent control between spring and soft winter wheat was 5 to $20 \%$ for $\bar{C}_{I N D}$ and 7 to $16 \%$ for $\bar{C}_{D O N}$. Based on the mean log ratios and between-study variances, the probability that IND or DON in a treated plot from a randomly selected study was lower than that in the check by a fixed margin was determined, which confirmed the superior efficacy of prothioconazole, metconazole, and tebuconzole+prothioconzole for Fusarium head blight disease and toxin control.
\end{abstract} ity. Prothioconazole+tebuconazole was the most effective fungicide for IND, with a $\bar{C}_{I N D}$ of $52 \%$, followed by metconazole (50\%), prothioconazole $(48 \%)$, tebuconazole $(40 \%)$, and propiconazole $(32 \%)$. For
Additional keywords: baseline risk, Fusarium graminearum, Gibberella zeae, linear mixed models, risk analysis, wheat scab.
Fusarium head blight of wheat (Triticum aestivum L.), caused predominantly by Fusarium graminearum Schwabe (teleomorph: Gibberella zeae (Schwein.) Petch), continues to be a concern throughout the world, causing substantial grain yield and quality losses almost every year in some major wheat-growing region. Efforts to minimize the impact of this disease and the associated toxin, deoxynivalenol (DON), produced by F. graminearum, have been based on the use of management strategies such as host resistance, crop rotation, tillage, and fungicide application. However, none of these methods used alone has been fully effective; high variability in response to fungicides, for example, for Fusarium head blight and DON, makes it difficult to confidently select the best product. Of the fungicides most widely tested against this disease, fungicides with triazole chemistry (e.g., tebuconazole) have been the most effective, giving the most consistent results $(4,11,17,19,20,24,35-37)$. However, even among triazoles or for a given triazole, efficacy varies among studies (45).

In a recent quantitative synthesis of the results from over 100 uniform fungicide trials (UFTs), Paul et al. (45) showed that the

Corresponding author: L. V. Madden; E-mail address: madden.1@osu.edu

doi:10.1094/PHYTO-98-9-0999

This article is in the public domain and not copyrightable. It may be freely reprinted with customary crediting of the source. The American Phytopathological Society, 2008. efficacy of $38.7 \%$ tebuconazole (Folicur 3.6 F; Bayer Cropscience, Research Triangle Park, NC), the longstanding industry standard for Fusarium head blight and DON control, varies among individual studies and is influenced by wheat type. The overall mean percent control was $40 \%$ for disease index and $22 \%$ for DON $(17,43,45)$. Tebuconazole is generally most effective at reducing Fusarium head blight and DON at moderate disease and toxin levels $(17,43,45)$ and when applied to moderately resistant cultivars rather than to susceptible cultivars (38).

Besides tebuconazole, other triazole-based fungicides have been tested against Fusarium head blight and DON, with some showing numerically, but not always statistically, superior efficacy relative to tebuconazole in individual studies $(17,43)$. One such fungicide is the recently registered $41 \%$ prothioconazole (Proline $480 \mathrm{SC}$; Bayer Cropscience, Research Triangle Park, NC). In some individual studies, when used as a solo active ingredient or in combination with tebuconazole (either as a premix or a tank mix), this product contributed to significantly greater reduction in visual symptoms of Fusarium head blight and DON contamination of grain than tebuconazole alone $(17,43)$. In other studies, however, the difference in efficacy was merely numerical $(34,43)$. Similar results were observed in comparisons between metconazole and tebuconazole $(9,17,23,33,43,57)$, suggesting that study- or environment-specific factors were probably influencing the overall and relative performance of these fungicides.

Knowledge of the overall and relative efficacy of fungicides is critical not only for selecting products for disease control but also 
for decision-making regarding federal registration of fungicides and for establishing standards for testing new active ingredients. Traditionally, attempts to compare fungicides for efficacy against Fusarium head blight and DON have been restricted to comparisons among treatments within individual studies and narrative comparisons of results across studies $(3,17,40,43)$. In these narrative or qualitative research syntheses, conclusions were drawn solely on the basis of tests of significance (a tally of the number of studies with significant results, i.e., $P<0.05$ ), without accounting for inherent differences among studies that likely influenced the magnitude and precision of the fungicide effects. Hedges and Olkin (16) and Hunter and Schmidt (25), among others, showed how such an approach can lead to totally erroneous conclusions. For reasons discussed elsewhere $(13,15,25,29,44)$, meta-analysis, which is quantitative research synthesis, provides an excellent alternative to significance tallying for integrating and interpreting results from multiple individual studies. An overall (mean) effect size, with associated standard error, is obtained to characterize the effect of treatment across all studies. The approach, based on random-effects and mixed-effects models (59), has high statistical power even when individual studies have low power.

We propose herein an expansion of a previous meta-analysis of the effect of tebuconazole on Fusarium head blight and DON (45) to evaluate the effects of other triazole-based fungicides relative to the control and also relative to tebuconazole for this disease and toxin, and to determine whether the effects were influenced by wheat type, disease level, and DON level. We utilized multivariate meta-analysis $(1,2,53,59)$ because of the multiple treatments (and associated effect-sizes) involved in each study that needed to be combined across studies. Multivariate meta-analysis is a newly developing field with some unique statistical issues compared with the much more common univariate meta-analysis $(15,25,29,44)$.

\section{MATERIALS AND METHODS}

UFTs. Fungicide studies were conducted in fields across the U.S. soft winter wheat-producing region (Mid-Atlantic, southern, and Midwestern regions not including Iowa, Minnesota, and the Dakotas) and spring wheat-producing region (Iowa, Minnesota, and the Dakotas) between 1998 and 2005. These studies comprise the UFTs of the U.S. Wheat and Barley Scab Initiative, (USWBSI). Statistical results from these trials and an additional nine trials conducted with the same protocols between 1995 and 1997 (prior to the establishment of the national UFTs, but which served as the basis for the national UFTs) were considered in this investigation. A detailed description of the UFTs was provided previously (45). In brief, trials generally were conducted according to a standard protocol, using a susceptible or moderately susceptible cultivar and agronomic practices appropriate for each location. Plots were either planted into corn or wheat residue, or artificially infested with $F$. graminearum-infested kernels and mist-irrigated as a means of enhancing inoculum production, infection, and disease development.

The specific fungicide treatments varied from year to year; however, in all studies, an untreated check was used as the control and $38.7 \%$ tebuconazole (Folicur 3.6 F, applied at a rate of $292 \mathrm{ml}$ per hectare at anthesis, Feekes plant growth stage [GS] 10.5.1 [28]) as the standard against which other fungicides were compared. Propiconazole (Tilt 3.6 EC; Syngenta Crop Protection Inc., Greensboro, NC) was tested from 1995 to 2001 and in 2004; prothioconazole was tested as an experimental product under the code names AMS21619 in 2001 and 2002, and JAU6476 in 2003 and 2004; metconazole was tested under the trade name Caramba 90 SL (BASF Corporation Agricultural Products, Research Triangle Park, NC) in 2000 and 2001, and as the experimental products V-10116 in 2003 and 2004, and BAS555 in 2005; and a combination of tebuconazole and prothioconazole was tested as tank mixes of Folicur 3.6 F and AMS21619 in 2002, and Folicur $3.6 \mathrm{~F}$ and JAU6476 in 2003 and 2004, and a premix under the trade name Prosaro 421 SC (Bayer Cropscience, Research Triangle Park, NC) in 2005.

In some years, metconazole was applied at two different rates. For those years, only the most effective rate, based on mean disease index, was considered for analysis. For simplicity, tebuconazole-, propiconazole-, prothioconazole-, tebuconazole plus prothioconazole-, and metconazole-based products will be abbreviated as TEBU, PROP, PROT, TEBU+PROT, and METC, respectively, when required in statistical notation. Some treatments were applied before and/or after anthesis in some studies, and in some instances multiple applications were made. For the purpose of this investigation, only treatments with a single application at anthesis were considered. In total, TEBU was tested in 152 studies for Fusarium head blight index and 108 studies for DON; PROP in 68 studies for index and 45 for DON; PROT in 71 studies for index and 60 for DON; TEBU+PROT in 78 studies for index and 58 for DON; and METC in 79 studies for index and 56 for DON. The nonionic surfactant, Induce (Helena Chemical Company, Collierville, TN), was added to each treatment at a rate of $0.125 \%$, vol/vol, and applications were made with $\mathrm{CO}_{2}$-pressurized sprayers, equipped with Twinjet XR8002 nozzles or paired XR8001 nozzles, mounted at an angle $\left(30\right.$ or $\left.60^{\circ}\right)$ forward and backward.

Fusarium head blight index (mean percentage of diseased spikelets per spike) was assessed at Feekes GS 11.2 (soft dough) and grain DON content (in parts per million) quantified at harvest as previously described $(14,35,42)$. In general, 20 to 50 spikes per plot were assessed, and 50 to $100 \mathrm{~g}$ of grain (or number of seeds) was ground for subsequent quantification of toxin.

Quantitative synthesis of fungicide efficacy. Effect sizes. Mean disease index and DON from fungicide-treated and untreated check plots were used to evaluate the efficacy of each fungicide relative to the control (with the means from the untreated check plot used as the reference). Moreover, means from each treatment other than tebuconazole were used to determine the efficacy of propiconazole, prothioconazole, tebuconazole+ prothioconazole, and metconazole relative to tebuconazole (with the means from tebuconazole-treated plots used as the reference). Following Hedges et al. (15) and Paul et al. (45), we used the log of the response ratio as the effect size of interest in the analysis. An effect size is any statistic that can be used to evaluate the overall effect of some treatment or the strength of a relationship between variables (29). If $\bar{X}_{\text {Check }}$ is the mean of index or DON for the untreated check in a single study, and $\bar{X}_{\text {Treated }}$ is the mean of index or DON for a treatment (either TEBU, PROP, PROT, TEBU+PROT, or METC), then the response ratio is $R^{(C)}=\bar{X}_{\text {Treated }} / \bar{X}_{\text {Check }}$. The log response ratio is given as

$$
L^{(C)}=\ln \left(R^{(C)}\right)=\ln \left(\bar{X}_{\text {Treated }} / \bar{X}_{\text {Check }}\right)=\ln \left(\bar{X}_{\text {Treated }}\right)-\ln \left(\bar{X}_{\text {Check }}\right)
$$

The log response ratio relative to TEBU is given as

$$
L^{(T)}=\ln \left(R^{(T)}\right)=\ln \left(\bar{X}_{\text {Treated }} / \bar{X}_{\text {TEBU }}\right)=\ln \left(\bar{X}_{\text {Treated }}\right)-\ln \left(\bar{X}_{\text {TEBU }}\right)
$$

Hedges et al. (15) and Paul et al. (45) give the statistical advantages of the use of $L$ in a meta-analysis. When referring to a $\log$ ratio generically, we simply use the symbol $L$ without a superscript label. To refer to the specific treatment in the numerator of the ratio, we add a second superscript. For instance, for propiconazole as the "Treated", we would specifically write $L^{(P R O P, C)}$ and $L^{(P R O P, T)}$. Percent control (for either index or DON)-that is, percent reduction in the response variable relative to the controlfor a given treatment in a study is given by $C=\left(1-R^{(C)}\right) \cdot 100$ (Paul et al. [45]). Percent reduction in index or DON in a treatment relative to value in the TEBU treatment in a study is given by $T=$ $\left(1-R^{(T)}\right) \cdot 100$. 
Multivariate random-effects meta-analysis. With only one treatment and a check, a univariate meta-analysis can be performed (for index or DON) based on the $L$ value for each study (together with the estimated variance of $L$ for each study) $(15,45)$. This is done by using $L$ as the response variable in a random-effects or mixed-effects linear model fitted to the data. However, with multiple treatments, there are several different $L$ values for each study, corresponding to each of the applied treatments (specifically, five different $L^{(C)}$ values in this case; $L^{(P R O P, C)}, L^{(P R O T, C)}$, etc.). Although one could conduct five different univariate metaanalyses, this approach has several problems (2). Among other things, the separate analyses fail to account for any correlations of the different $L$ values (for either index or DON) within or between studies; by definition, the $L$ values within a study are functionally related because they all use the same denominator in the response ratio (i.e., mean for the check). The univariate approach would also not allow direct comparison of any treatment mean relative to the TEBU mean unless another collection of meta-analyses were performed (specifically, for the four $L^{(T)}$ values; $L^{(P R O P, T)}, L^{(P R O T, T)}$, etc.). Thus, multivariate analyses were performed instead. As stated by Arends et al. (2), a multivariate meta-analysis "gives a complete and concise description of all data at one stroke."

Multivariate analysis is based on a vector of responses for each study. Instead of using a vector of $L$ values, a vector consisting of the $\log$ of the treatment means was used for each study. For a single study, we can define the log mean for a given treatment as $Y_{j}=\ln \left(\bar{X}_{j}\right)$, where $j$ is an index for the specific treatment $(j=$ TEBU, PROP, PROT, TEBU+PROT, METC, or check). The vector of responses $(\mathbf{Y})$ can be written as

$$
\mathrm{Y}=\left(\begin{array}{l}
\ln \left(\bar{X}_{\text {TEBU }}\right) \\
\ln \left(\bar{X}_{\text {PROP }}\right) \\
\ln \left(\bar{X}_{\text {PROT }}\right) \\
\ln \left(\bar{X}_{\text {TEBU }+ \text { PROT }}\right) \\
\ln \left(\bar{X}_{\text {METC }}\right) \\
\ln \left(\bar{X}_{\text {Check }}\right)
\end{array}\right)=\left(\begin{array}{l}
Y_{\text {TEBU }} \\
Y_{\text {PROP }} \\
Y_{\text {PROT }} \\
Y_{\text {TEBU+PROT }} \\
Y_{\text {METC }} \\
Y_{\text {Check }}
\end{array}\right)
$$

The variance of the log means for each individual study, known as the within-study or sampling variance, is given by $s_{j}^{2}=V /\left(n \cdot \bar{X}_{j}^{2}\right)$, where, as before, the $j$ subscript refers to the specific treatment and $n$ is the number of replicates (usually $n=4$ ). $V$ is the residual variance or mean square error for the individual study in which disease index or DON was analyzed. The treatment means within the individual studies are uncorrelated because the data come from different plots; thus, the covariance of the means within studies are all 0 . One can define the variance-covariance matrix for $\log$ means (i.e., the $Y_{j}$ values) for an individual study as $\mathbf{S}$, which is a $6 \times 6$ matrix (for the six treatments, including the check). The diagonal elements of $\mathbf{S}$ are the $s_{j}^{2}$ within-study variance values described above, and all other elements are 0 (because of the 0 covariances or correlations).

With $K$ studies in the meta-analysis, one can define the response for the $i$ th study $(i=1, \ldots, K)$ and the $j$ th treatment as $Y_{i j}=$ $\ln \left(\bar{X}_{i j}\right)$. The vector of responses for the $i$ th study is given as $\mathbf{Y}_{i}$. The within-study variance-covariance matrix is given as $\mathbf{S}_{i}$ (which is different for each study); the diagonal elements of $\mathbf{S}_{i}$ are $s_{i j}^{2}$ (i.e., the variances depend on both the treatment $[j]$ and the study $[i]$ ), and the off-diagonal elements are 0 . The mean (expected value) of the response vector $\mathbf{Y}_{i}$ over the $K$ studies is represented by parameter vector $\mu$. The vector can be written as

$$
\mu=\left(\begin{array}{l}
\mu_{T E B U} \\
\mu_{\text {PROP }} \\
\mu_{\text {PROT }} \\
\mu_{\text {TEBU+PROT }} \\
\mu_{\text {METC }} \\
\mu_{\text {Check }}
\end{array}\right)
$$

The elements are the individual mean or expected $Y_{j}\left[\ln \left(\bar{X}_{j}\right)\right]$ values for the different treatments across the $K$ studies; the estimates of the elements of $\boldsymbol{\mu}$ are the estimated means across all the studies (i.e., $\hat{\mu}_{j}=\bar{Y}_{j}$ ).

In the meta-analysis, we assume that $\mathbf{Y}_{i}$ has a multivariate normal distribution with mean vector $\mu$ and variance-covariance matrix $\Sigma+\mathbf{S}_{i}$, where $\Sigma$ is a $6 \times 6$ between-study variancecovariance matrix. The model can be written as

$$
\mathbf{Y}_{i} \sim N\left(\mu, \Sigma+\mathbf{S}_{i}\right)
$$

where $N(\bullet)$ indicates here a multivariate normal distribution. Because of the nonzero between-study variances, equation 2 represents a multivariate random-effects meta-analysis model. We used an unstructured matrix for $\Sigma$, in the sense that there were no constraints placed on the variances for each treatment and covariances for pairs of treatments. Although there is no correlation of $\log$ means within studies (because they originate in different plots), log means from different treatments may be correlated between studies (2). For instance, if the magnitude of disease index (or DON) depends on weather or other conditions in each study, then there likely will be a positive correlation of the log means across studies. The model in equation 2 is similar to the one used in section 10.2 of Whitehead (61) and to equation 2 in $\mathrm{Lu}$ and Ades (31), although both of those references used a simpler structure for $\Sigma$. By modeling the log means and not the $\log$ ratios directly, one avoids the complicating statistical issue of the response variables all being a function of the same denominator. Equation 2 is a natural extension of the standard randomeffects meta-analysis model, $Y_{i} \sim N\left(\mu, \sigma^{2}+s_{i}^{2}\right)$, where $\sigma^{2}$ is the between-study variance (29). Equation 2 was fitted to the data from the total of 165 studies with the MIXED procedure of SAS (30; SAS Institute, Cary, NC), as described by van Houwelingen et al. (59), using maximum likelihood. Separate analyses were performed for index and DON. Based on the Akaike information criterion (AIC) statistic (30), equation 2 with an unstructured $\Sigma$ matrix fitted better than when simpler structures were used for $\Sigma$, such as a single correlation for all pairs or treatments or a between-study variance that was the same for all treatments (L. V. Madden, unpublished data). With maximum-likelihood parameter estimation, results from all treatments of all studies are utilized, even though all treatments do not occur in every study $(2,55)$. The within-study variances (the elements of $\mathbf{S}_{i}$ ) were incorporated into the model fitting procedure by weighting each observation by the inverse of the within-study variance $\left(s_{i j}^{2}\right)$. The mean effect size of interest is the difference of pairs of elements of $\mu$. In this sense, the actual elements of the $\mu$ vector can be considered "nuisance parameters" (31), since they are only intermediate terms in the final parameter estimation.

As an example, the estimated mean log response ratio for propiconazole versus the check is given by

$$
\bar{L}^{(P R O P, C)}=\hat{\mu}_{P R O P}-\hat{\mu}_{\text {Check }}=\bar{Y}_{P R O P}-\bar{Y}_{\text {Check }}
$$

The estimated mean log response ratio for propiconazole versus tebuconazole is given by

$$
\bar{L}^{(P R O P, T)}=\hat{\mu}_{P R O P}-\hat{\mu}_{T E B U}=\bar{Y}_{P R O P}-\bar{Y}_{T E B U}
$$

Using the differences of estimated $\mu$ values, all the required mean $\log$ ratios $\left(\bar{L}^{(C)}, \bar{L}^{(T)}\right.$, or in general, $\left.\bar{L}\right)$ were determined. This operation takes advantage of the fact that a difference in logs is equal to the $\log$ of the ratio (equations $1 \mathrm{a}$ and $\mathrm{b}$, for instance). Both contrast and lsmeans statements in MIXED were utilized to obtain the contrast estimates, as well as the associated standard errors and 95\% confidence intervals. The standard errors are based on the within- and between-subject variances and betweensubject covariances (59). 
A standard normal test statistic $(Z ; 15,25,29,45)$ was used to determine whether the log ratios involving the control $\left(\bar{L}^{(C)}\right)$ or tebuconazole $\left(\bar{L}^{T)}\right)$ were significantly different from zero, for each of the treatments, for both index and DON. The $R^{2}$ statistic of Higgins and Thompson (22) was used to quantify the impact of between-study variability on the $Z$ statistic and confidence intervals for the $\log$ ratios in order to determine if a simpler fixedeffects meta-analysis could have been used instead of the randomeffects analysis. Values of the $R^{2}$ statistic (which is not a coefficient of determination) above 1.5 indicate considerable influence of the between-study variances on the results. For all effect sizes in this investigation (log ratios for each treatment), $R^{2}$ was greater than 5 for Fusarium head blight index and above 3 for DON (L. V. Madden, unpublished data), justifying the use of the more complicated random-effects analysis.

Mean response ratios and confidence intervals were approximated by back-transforming $\bar{L}$ values, and back-transforming the limits of the $95 \%$ confidence intervals for $\bar{L}$. For example, mean response ratio (for any given treatment) relative the control is estimated by $\bar{R}^{(C)}=\exp \left(\bar{L}^{(C)}\right)$, and relative to tebuconazole, is given by $\bar{R}^{(T)}=\exp \left(\bar{L}^{(T)}\right)$ (equations 1a and b). These are approximations because the exact mean ratio is a somewhat more complicated function of the mean log ratio than the simple back-transformation (14), although the approximation is good. From the mean response ratios, mean percent control $(\bar{C})$ was approximated for each fungicide treatment for both index and DON as previously described (46). In particular,

$$
\bar{C}=\left(1-\bar{R}^{(C)}\right) \cdot 100
$$

Confidence intervals for $\bar{C}$ were obtained by transforming the limits of the intervals for the response ratios. The mean percent of each treatment mean relative to tebuconazole $(T)$ was likewise calculated based on the relevant response ratio

$$
\bar{T}=\left(1-\bar{R}^{(T)}\right) \cdot 100
$$

Influence of moderator variables on fungicide efficacy. The multivariate meta-analysis model was expanded to evaluate the influence of wheat type, Fusarium head blight and DON levels in the untreated check (used as a measure of disease- and DONfavorable conditions), and year on the overall mean log response ratios (effect sizes). Studies were categorized as spring and winter wheat studies based on the wheat type used. Year was considered a continuous variable in an analysis to determine if magnitude of effect size systematically changed over time.

To be consistent with Paul et al. (45), studies were grouped into three categories-using disease index thresholds of 2 and $15 \%$, and DON thresholds of 1 and $10 \mathrm{ppm}$ - on the bases of mean index and DON levels in the check plots. An index of $2 \%$ corresponds to a mean incidence of approximately $14 \%$ (46), and is generally consistent with what is considered an epidemic in some Fusarium head blight risk assessments (41). An index of $15 \%$ was considered a high value and corresponds to the estimated mean level of disease across UFTs at which expected DON $=5 \mathrm{ppm}$ (U.S. Food and Drug Administration [FDA] advisory level for DON in grain and grain by-products destined for animals other than cattle and chicken), based on a meta-analysis of the relationship between index and DON (46). A DON level of 1 ppm represents the FDA advisory level for DON in wheat products destined for human consumption, whereas 10 ppm represents FDA's advisory level for DON in grain and grain by-products destined for consumption by cattle and chicken. Based on mean index, studies were categorized as (i) studies with $\bar{X}_{I N D} \leq 2 \%$, (ii) studies with $\bar{X}_{I N D}$ between 2 and $15 \%$, and (iii) studies with $\bar{X}_{I N D} \geq 15 \%$. Similarly, on the bases of mean DON, studies were grouped into those with (i) $\bar{X}_{D O N}<1 \mathrm{ppm}$, (ii) $\bar{X}_{D O N} \geq 1$ and $<10 \mathrm{ppm}$, and (iii) $\bar{X}_{D O N} \geq 10 \mathrm{ppm}$.
The moderator variables-wheat type category, index level category (in the analysis with log mean index as the response), DON level category (in the analysis with log mean DON as the response), and year-were considered fixed effects. The effect of the moderator variable for the $i$ th study on the response vector is given by the vector $\delta_{i}$, with six rows (for the six treatments, including the check). The model can be written as

$$
\mathbf{Y}_{i} \sim N\left(\mu+\delta_{i}, \Sigma+\mathbf{S}_{i}\right)
$$

where all other terms are as defined previously. The expected log means for each treatment was no longer a constant vector $(\mu)$ but depended on the moderator variables in the particular study $(\mu+$ $\delta_{i}$ ). Elements of $\delta_{i}$ depended on the specific levels of the moderator variable(s) (e.g., spring versus winter wheat, year of study) for the $i$ th study.

A separate analysis was performed for each moderator variable, for both index and DON. Models were fitted in PROC MIXED, using the same (within-study) weights as above. Contrasts were used to estimate the mean effect sizes (i.e., mean log ratios for each treatment relative to the check and relative to TEBU) for each level of the categorical moderator variables; standard errors and confidence intervals were likewise calculated for these mean effect sizes. Back-transformations, as described above, were used to obtain mean and $95 \%$ confidence intervals percent control $(\bar{C})$ and percent TEBU ( $\bar{T}$ ) for each moderator-variable category.

Chi-square tests were used to determine if wheat type and year had a significant effect on the $\log$ response ratios (not on the $\mathbf{Y}_{i}$ values directly). In other words, we were not interested in whether or not the moderator variables directly affected log of mean index or mean DON, but whether the variables affected the differences in logs of disease index or DON between treatments (i.e., the log ratios). These tests were performed using additional contrast statements in the MIXED procedure.

Although mean log ratios were obtained for the categories of index and DON through the use of moderator variables, the test of significance was not obtained from the use of the moderator variable. Because the check and treatment log means (and, hence, differences in $\operatorname{logs}$, the $\log$ ratios) were all part of the same response vector for the $i$ th study $\left(\mathbf{Y}_{i}\right)$, there is a direct approach for determining if there is a continuous relationship between the $\log$ ratio and the $\log$ of the check mean (2). The log ratio relative to the check for the $i$ th study is given as $L_{i}^{(C)}$ and the log check mean for the $i$ th study is given as $Y_{i, \text { Check }}$. A model for the relation is given as

$$
L_{i}^{(C)}=Y_{i, \text { Treated }}-Y_{i, \text { Check }}=\gamma_{0}+\gamma_{1} Y_{i, \text { Check }}
$$

where $\gamma_{0}$ and $\gamma_{1}$ are parameters to be estimated. If there is a relationship between the mean disease (or DON) level in the untreated check, as measured by the log mean, and the log ratio, then the slope $\gamma_{1}$ will be different from 0 . The estimate of the slope was obtained directly from the fit of equation 2 to the data as part of the meta-analysis, specifically as

$$
\hat{\gamma}_{1}=1-\left[\hat{\sigma}_{\text {Treated,Check }} / \hat{\sigma}_{\text {Check }}^{2}\right]
$$

where $\hat{\sigma}_{\text {Treated,Check }}$ is the estimated between-study covariance between the two variables listed, and $\hat{\sigma}_{\text {Check }}^{2}$ is the estimated between-study variance of the log check means. Both are elements of $\hat{\Sigma}$, the estimated variance-covariance matrix of equation 2 . A standard normal test was performed by dividing the estimated slope (equation 7) by its standard error. The NLMIXED procedure was used to directly obtain the standard error of the estimated slope based on the estimated standard errors of $\hat{\sigma}_{\text {Treated,Check }}$ and $\hat{\sigma}_{\text {Check }}^{2}$. Page 1347 of Arends et al. (2) and page 601 of van Houwelingen et al. (59) provide details on similar exercises in a multivariate meta-analysis. 
Probability of a positive percent control and a percent control $>\mathbf{2 5}$ and $\mathbf{5 0 \%}$. Based on the mean effect size (i.e., $\bar{L}^{(C)}$ ) for each of the treatments for both index and DON and the estimated between-study standard deviation for the log-ratio $\left(\hat{\sigma}^{(C)}\right)$, one can calculate the probability that a new (single) randomly selected study - done in the same way as the studies used in this analysis-will have a positive percent control for the selected treatment $(C>0)$, which is equivalent to the probability that $L^{(C)}<$ $0(45,59)$. This can be viewed as a component of a quantitative risk analysis (51). The estimated standard deviation is given by

$$
\hat{\sigma}^{(C)}=\sqrt{\hat{\sigma}_{\text {Treated }}^{2}+\hat{\sigma}_{\text {Check }}^{2}-2 \hat{\sigma}_{\text {Treated,Check }}}
$$

where the terms on the right side are elements of the estimated between-study variance covariance matrix $(\hat{\Sigma})$, specifically the estimates of the treatment variance, check variance, and covariance of the response between the treatment and check. The probability is estimated as $p_{+}^{(C)}=\Phi\left(-\bar{L}^{(C)} / \hat{\sigma}^{(C)}\right)$, where $\Phi(\bullet)$ is the cumulative standard-normal function. The probability was also estimated that a new randomly selected study will have a percent control greater than some chosen (fixed) nonzero value. For instance, the probability that a treatment of interest in a new study has a percent control greater than $50 \%(C>50 \%)$, equivalent to the probability that $L^{(C)}<-0.69$, is given by $p_{50}^{(C)}=$ $\Phi\left(\left(-0.69-\bar{L}^{(C)}\right) / \hat{\sigma}^{(C)}\right)$. The probability that a treatment has a percent control greater than $25 \%(C>25 \%)$, equivalent to the probability that $L^{(C)}<-0.288$, is given by $p_{25}^{(C)}=$ $\Phi\left(\left(-0.288-\bar{L}^{(C)}\right) / \hat{\sigma}^{(C)}\right)$.

The probability that a treatment in a new randomly selected study will have better control (i.e., lower index or DON) than found for the tebuconazole treatment $(T>0)$, which is equivalent to the probability that $L^{(T)}<0$, was estimated as $p_{+}^{(T)}=$ $\Phi\left(-\bar{L}^{(T)} / \hat{\sigma}^{(T)}\right)$. The estimated between-study standard deviation for this expression was given by

$$
\hat{\sigma}^{(T)}=\sqrt{\hat{\sigma}_{\text {Treated }}^{2}+\hat{\sigma}_{T E B U}^{2}-2 \hat{\sigma}_{\text {Treated,TEBU }}}
$$

Likewise, the probability that a treatment in a new randomly selected study has $25 \%$ or better control than found for the tebuconazole treatment $(T>25 \%)$, equivalent to the probability that $L^{(T)}<-0.288$, is calculated by $p_{25}^{(T)}=\Phi\left(\left(-0.288-\bar{L}^{(T)}\right) / \hat{\sigma}^{(T)}\right)$.

\section{RESULTS}

Fusarium head blight and DON levels. In general, disease levels, based on mean index from untreated check plots were similar among winter and spring wheat studies, ranging from 0 to $55 \%$ (Fig. 1A). Fifty percent of the spring wheat studies had mean index in the untreated plots between 5.5 and 26.6\%, whereas the corresponding range for winter wheat studies was between 1.3 and $22.0 \%$. In both sets of studies, the overall mean level of disease was lower in fungicide-treated plots than in the untreated
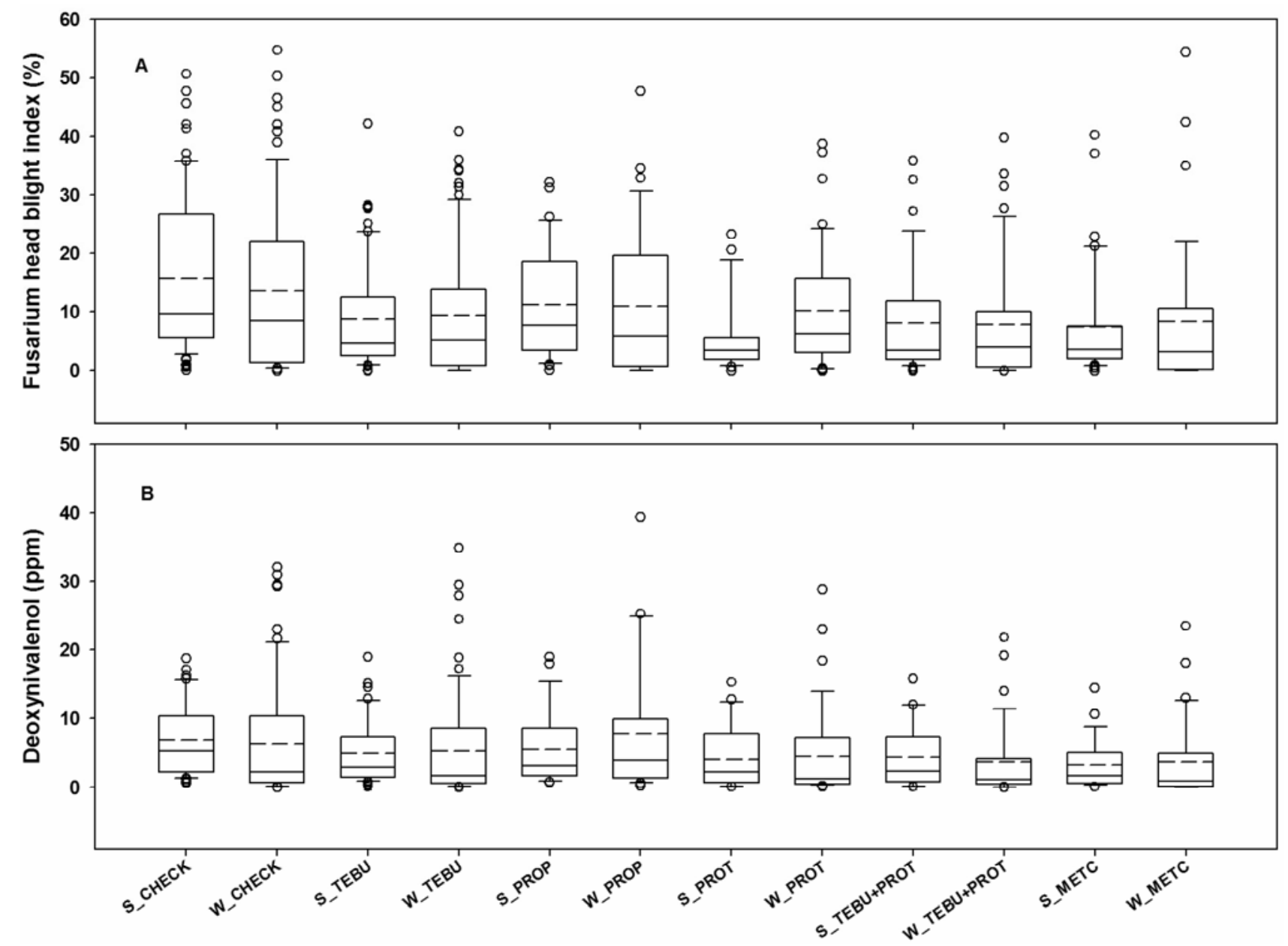

Fig. 1. Box plots summarizing A, distribution of mean Fusarium head blight index (mean percentage of diseased spikelets per spike) and B, deoxynivalenol content of harvested wheat grain (parts per million [ppm]) for wheat plots treated with tebuconazole (TEBU), propiconazole (PROP), prothioconazole (PROT), a mixture of tebuconazole and prothioconazole (TEBU+PROT), and metconazole (METC), and untreated check plots from winter (W) and spring (S) wheat studies. The broken and solid lines within the box represent the mean and median, respectively, whereas the top and bottom lines of the box represent the 75th and 25th percentiles of the data, respectively. Vertical bars extending beyond the boxes represent the 10th and 90th percentiles, and circles indicate outliers. 
check plots. However, for all fungicide treatments, mean index was within a narrower range in spring wheat studies than in winter wheat studies. For instance, for the prothioconazole treatment, mean index ranged from 0 to $23.3 \%$ in spring wheat compared with 0 to $38.7 \%$ in winter wheat (Fig. 1A).

The overall level of DON, based on means from untreated check plots, was slightly higher in spring wheat studies $(6.9 \mathrm{ppm})$ than in winter wheat studies $(6.4 \mathrm{ppm})$; however, the range of mean DON was wider in the latter than in the former group of studies (Fig. 1B). For instance, for the metconazole treatment, the range of mean DON was between 0 and $23.5 \mathrm{ppm}$ for winter and between 0.1 and 14.5 for spring wheat. Among winter wheat studies, $50 \%$ had mean DON in the untreated check between 0.70 and $10.25 \mathrm{ppm}$, while $50 \%$ of the spring wheat studies had mean DON between 2.26 and $10.40 \mathrm{ppm}$. In general, fungicide-treated plots tended to have lower levels of DON than the untreated check plots. However, depending on the fungicide, between 41 and $64 \%$ of winter wheat studies and 46 and $67 \%$ of spring wheat studies had mean DON > 2 ppm in fungicide-treated plots.

Overall fungicide efficacy. Comparisons with the check. The efficacies of fungicides evaluated in this investigation for the control of Fusarium head blight and DON were assessed on the bases of the magnitude and significance of mean log-transformed response ratios $\left(\bar{L}^{(C)}\right.$; equation $3 a$ ) for each treatment relative to the check. From the $\bar{L}^{(C)}$ values, the corresponding (approximate) mean percent controls ( $\bar{C}$; equation $4 \mathrm{a}$ ) and their confidence intervals were obtained. By definition (45), large negative $\bar{L}^{(C)}$ corresponds to large positive $\bar{C}$, which is interpreted as an indication of high efficacy. For all fungicides, for both disease index and DON, $\bar{L}^{(C)}$ was significantly different from zero, based on the standard normal test in the meta-analysis $(P<0.001$, Table $1)$. For index, $\bar{L}^{(C)}$ had the largest negative value for tebuconazole+prothioconazole, followed by metconazole, prothioconazole, tebuconazole, and propiconazole. The corresponding mean percent control values were 51.8, 49.8, 48.3, 40.0, and $31.6 \%$ for tebuconazole+prothioconazole, metconazole, prothioconazole, tebuconazole, and finally propiconazole, respectively.

Metconazole, prothioconazole, and tebuconazole+prothioconazole also resulted in the greatest reduction in DON relative to the untreated check, with $\bar{C}$ values of $45.1,42.9$, and $41.7 \%$, respectively (Table 1$)$, followed by tebuconazole $(\bar{C}=22.9 \%)$ and propiconazole ( $\bar{C}=12.2 \%$ ). For both index and DON, the width of the $95 \%$ confidence interval around $\bar{C}$ was widest for propiconazole and narrowest for tebuconazole, probably reflecting, at least in part, the fact these two products had the smallest and largest number of studies in the meta-analysis, respectively. Overall, mean percent control was greater for index than for DON for any given fungicide.

Comparisons with tebuconazole. Using tebuconazole as the standard for comparison (the denominator of the response ratio in equation $1 \mathrm{~b}$ ), rather than the check, mean log-transformed response ratios $\left(\bar{L}^{T)}\right.$; equation $3 \mathrm{~b}$ ) and significance levels were used to evaluate the efficacy of each fungicide relative to tebuconazole. For each product, $\bar{T}$ was approximated from $\bar{L}^{(T)}$ as described for equation $4 \mathrm{~b}$. A negative $\bar{L}^{(T)}$ value, and a corresponding positive $\bar{T}$ value, indicates that the tested product performed better than tebuconazole, whereas a positive $\bar{L}^{(T)}$ value, and corresponding negative $\bar{T}$ value, indicates that the efficacy of the product was inferior to that of tebuconazole. $\bar{L}^{(T)}$ values for index and DON were significantly different from zero, based on the standard normal test of the meta-analysis $(P<0.001$, Table 2), for each of the fungicides. For both index and DON, propiconazole was significantly less effective than tebuconazole, with $\bar{T}$ values of $-13.9 \%$ for index and $-12.8 \%$ for DON. All other products showed significantly superior efficacy relative to tebuconazole, with negative $\bar{L}^{(T)}$ and corresponding positive $\bar{T}$ values (Table 2). For index, tebuconazole+prothioconazole had the highest $\bar{T}(19.8 \%)$, followed by metconazole and prothioconazole. For DON, metconazole had the highest $\bar{T}(28.8 \%)$ followed by prothioconazole and tebuconazole+prothioconazole; based on the similarity of their corresponding $\bar{L}^{(T)}$ and $\bar{T}$ values, prothioconazole and tebuconazole+prothioconazole had similarly superior efficacy relative to tebuconazole at reducing DON (Table 2 ). The index and DON responses to the propiconazole treatment relative to the tebuconazole treatment were the most variable, based on the width of the $95 \%$ confidence interval around $\bar{T}$ ( $14.7 \%$ in both cases).

Influence of moderator variables on fungicide efficacy. Effects of wheat type. Wheat type had a significant influence on the effect sizes (based on the chi-square statistics from the contrast statement $)(P<0.05)$ for several fungicides. For index, wheat type significantly affected $\bar{L}^{(C)}$ for all fungicides with the exception of propiconazole, with spring wheat having significantly lower $\bar{L}^{(C)}$ values, and correspondingly higher $\bar{C}$ values, than winter wheat (Table 3). For instance, mean percent control was $45.7 \%$ versus $32.3 \%$ for tebuconazole in spring and winter wheat, respectively. Similarly, for DON, for three of the fungicides tested, tebuconazole, propiconazole, and metconazole,

TABLE 1. Log of the response ratio (effect size), percent control, and corresponding statistics for the effect of triazole-based fungicides on Fusarium head blight index and deoxynivalenol accumulation in wheat

\begin{tabular}{|c|c|c|c|c|c|c|c|c|c|c|c|}
\hline \multirow[b]{2}{*}{ Response $^{\mathrm{a}}$} & \multirow[b]{2}{*}{ Fungicide $^{\mathrm{b}}$} & \multirow[b]{2}{*}{$K^{\mathrm{c}}$} & \multicolumn{6}{|c|}{ Effect size $^{\mathrm{d}}$} & \multicolumn{3}{|c|}{ Mean percent control ${ }^{\mathrm{e}}$} \\
\hline & & & $\bar{L}^{(C)}$ & $\operatorname{se}\left(\bar{L}^{(C)}\right)$ & $C I_{L}$ & $C I_{U}$ & $Z$ & $P$ & $\bar{C}$ & $C I_{L}$ & $C I_{U}$ \\
\hline \multirow[t]{4}{*}{ IND } & TEBU & 143 & -0.51 & 0.036 & -0.58 & -0.44 & -14.11 & $<0.001$ & 40.00 & 35.60 & 44.01 \\
\hline & PROP & 63 & -0.38 & 0.044 & -0.47 & -0.29 & -8.65 & $<0.001$ & 31.61 & 25.17 & 37.50 \\
\hline & TEBU+PROT & 73 & -0.73 & 0.052 & -0.83 & -0.63 & -14.01 & $<0.001$ & 51.81 & 46.74 & 56.40 \\
\hline & METC & 71 & -0.69 & 0.052 & -0.80 & -0.59 & -13.22 & $<0.001$ & 49.84 & 44.57 & 55.07 \\
\hline \multirow[t]{3}{*}{ DON } & TEBU & 104 & -0.26 & 0.029 & -0.31 & -0.20 & -8.66 & $<0.001$ & 22.89 & 18.13 & 26.66 \\
\hline & TEBU+PROT & 56 & -0.54 & 0.050 & -0.64 & -0.45 & -10.99 & $<0.001$ & 41.73 & 36.24 & 47.27 \\
\hline & METC & 50 & -0.60 & 0.050 & -0.70 & -0.50 & 11.85 & $<0.001$ & 45.12 & 39.35 & 50.34 \\
\hline
\end{tabular}

${ }^{\mathrm{a}}$ IND = Fusarium head blight index (mean proportion of diseased spikelets per spike) and DON = deoxynivanenol content of harvested grain (ppm).

b Active ingredients TEBU $=$ tebuconazole, $\mathrm{PROP}=$ propiconazole, $\mathrm{PROT}=$ prothioconazole, and METC $=$ metconazole.

${ }^{c}$ Total number of studies used in each analysis (based on the number of studies in which the indicated variable was measured for the specific fungicide treatment and the control).

${ }^{\mathrm{d}} \bar{L}^{(C)}=$ Mean log-transformed response ratio for each treatment mean relative to the check mean (equations 1a and $\left.3 \mathrm{a}\right)$; $\operatorname{se}\left(\bar{L}^{(C)}\right)=\operatorname{standard}$ error of $\bar{L}^{(C)}$; lower $\left(C I_{L}\right)$ and upper $\left(C I_{U}\right)$ limits of the $95 \%$ confidence interval around $\bar{L}^{(C)}$; and $Z$ (standard normal) statistic from the meta-analysis. $P=$ probability value (significance level).

${ }^{\text {e }}$ Mean percent control $(\bar{C})$ and lower $\left(C I_{L}\right)$ and upper $\left(C I_{U}\right)$ limits of the $95 \%$ confidence interval for $\bar{C}$, based on equation 4 a and $\bar{L}^{(C)}$, and the confidence limits for $\bar{L}^{(\text {) }}$ 
wheat type had a significant effect on $\bar{L}^{(C)}$, with spring wheat again having significantly lower $\bar{L}^{(C)}$ and higher $\bar{C}$ values than winter wheat. Based on mean percent control from spring wheat studies, metconazole was the most effective fungicide in reducing both index and DON ( $\bar{C}$ of 58.1 and $52.3 \%$, respectively), followed closely by tebuconazole+prothioconazole ( $\bar{C}$ of 57.3 and $47.8 \%$, respectively) and prothioconazole ( $\bar{C}$ of 53.7 and $46.7 \%$, respectively) (Table 3 ). For winter wheat studies, tebuconazole+prothioconazole was the most effective fungicide for disease control $(\bar{C}=44.6 \%)$, followed by prothioconazole, whereas prothioconazole was the most effective for DON control $(\bar{C}=$ $39.4 \%$ ), followed closely by tebuconazole+prothioconazole and metconazole (Table 3).
For index, wheat type had a significant effect $(P<0.05)$ on the $\log$ response ratio relative to tebuconazole $\left(L^{(T)}\right)$ for the propiconazole and metconazole treatments, but not for the prothioconazole and tebuconazole+prothioconazole treatments (Table 4). For propiconazole, control of index was poorer in spring wheat ( $\bar{T}=-20.9 \%)$ than in winter wheat $(\bar{T}=-5.1 \%)$, relative to the tebuconazole treatment. For metconazole, control of index was greater in spring wheat $(\bar{T}=22.9 \%)$ than in winter wheat $(\bar{T}=$ $8.6 \%$ ), relative to tebuconazole. For prothioconazole and tebuconazole+prothioconazole, the $\bar{L}^{T)}$ values (and corresponding $\bar{T}$ values) were similar between winter and spring wheat studies (and not significantly different), suggesting that unlike metconazole and propiconazole, the efficacy of prothioconazole and tebu-

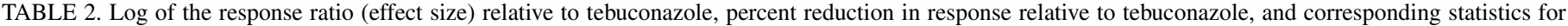
efficacy of other triazole-based fungicides for Fusarium head blight index and deoxynivalenol accumulation in wheat

\begin{tabular}{|c|c|c|c|c|c|c|c|c|c|c|c|}
\hline \multirow[b]{2}{*}{ Response $^{\mathrm{a}}$} & \multirow[b]{2}{*}{ Fungicide $^{\mathrm{b}}$} & \multirow[b]{2}{*}{$K^{\mathrm{c}}$} & \multicolumn{6}{|c|}{ Effect size ${ }^{\mathrm{d}}$} & \multicolumn{3}{|c|}{ Mean percent relative of TEBU ${ }^{\mathrm{e}}$} \\
\hline & & & $\bar{L}^{(T)}$ & $\operatorname{se}\left(\bar{L}^{T)}\right)$ & $C I_{L}$ & $C I_{U}$ & $Z$ & $P$ & $\bar{T}$ & $C I_{L}$ & $C I_{U}$ \\
\hline \multirow[t]{4}{*}{ IND } & PROP & 62 & 0.13 & 0.033 & 0.06 & 0.19 & 3.90 & $<0.001$ & -13.88 & -20.92 & -6.18 \\
\hline & PROT & 69 & -0.15 & 0.036 & -0.22 & -0.08 & -4.16 & $<0.001$ & 13.93 & 7.69 & 19.75 \\
\hline & TEBU+PROT & 73 & -0.22 & 0.036 & -0.29 & -0.15 & -6.08 & $<0.001$ & 19.75 & 13.93 & 25.17 \\
\hline & METC & 71 & -0.19 & 0.040 & -0.26 & -0.11 & -4.61 & $<0.001$ & 17.30 & 10.42 & 22.89 \\
\hline \multirow[t]{4}{*}{ DON } & PROP & 45 & 0.12 & 0.032 & 0.06 & 0.19 & 3.75 & $<0.001$ & -12.75 & -20.92 & -6.18 \\
\hline & PROT & 60 & -0.30 & 0.038 & -0.37 & -0.23 & -7.92 & $<0.001$ & 25.92 & 20.55 & 30.93 \\
\hline & TEBU+PROT & 55 & -0.29 & 0.039 & -0.36 & -0.21 & -7.48 & $<0.001$ & 25.17 & 18.94 & 30.23 \\
\hline & METC & 50 & -0.34 & 0.036 & -0.41 & -0.27 & -9.45 & $<0.001$ & 28.82 & 23.66 & 33.63 \\
\hline
\end{tabular}

${ }^{a}$ IND = Fusarium head blight index (mean proportion of diseased spikelets per spike) and DON = deoxynivanenol content of harvested grain (ppm).

b Active ingredients TEBU = tebuconazole, $\mathrm{PROP}=$ propiconazole, $\mathrm{PROT}=$ prothioconazole, and METC $=$ metconazole.

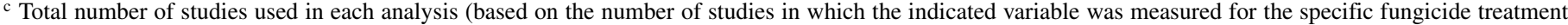
and tebuconazole).

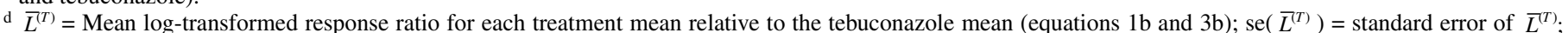
lower $\left(C I_{L}\right)$ and upper $\left(C I_{U}\right)$ limits of the $95 \%$ confidence interval around $\vec{L}^{(T)}$; and $Z$ (standard normal) statistic from the meta-analysis of the effect of fungicide treatments, relative to tebuconazole, on IND and DON. $P=$ probability value (significance level).

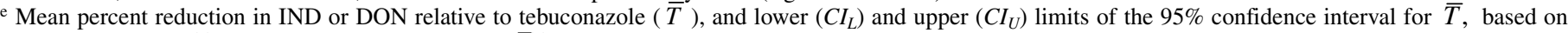
equation 4 b and $\bar{L}^{(T)}$, and the confidence limits for $\bar{L}^{(T)}$.

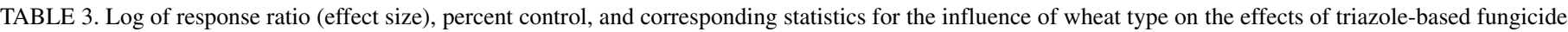
on Fusarium head blight index and deoxynivalenol accumulation in wheat

\begin{tabular}{|c|c|c|c|c|c|c|c|c|c|c|c|}
\hline \multirow[b]{2}{*}{ Response $^{a}$} & \multirow[b]{2}{*}{ Fungicide $^{b}$} & \multirow[b]{2}{*}{ Type $^{c}$} & \multirow[b]{2}{*}{$K^{\mathrm{d}}$} & \multicolumn{5}{|c|}{ Effect size $\mathrm{e}^{\mathrm{e}}$} & \multicolumn{3}{|c|}{ Percent control $^{\mathrm{f}}$} \\
\hline & & & & $\bar{L}^{(C)}$ & $\operatorname{se}\left(\bar{L}^{C)}\right)$ & $C I_{L}$ & $C I_{U}$ & $P$ & $\bar{C}$ & $C I_{L}$ & $C I_{U}$ \\
\hline \multirow[t]{10}{*}{ IND } & \multirow[t]{2}{*}{ TEBU } & Winter & 67 & -0.39 & 0.050 & -0.48 & -0.29 & \multirow[t]{2}{*}{0.001} & 32.29 & 25.17 & 38.12 \\
\hline & & Spring & 76 & -0.61 & 0.047 & -0.70 & -0.52 & & 45.66 & 40.55 & 50.34 \\
\hline & \multirow[t]{2}{*}{ PROP } & Winter & 27 & -0.34 & 0.065 & -0.46 & -0.21 & \multirow[t]{2}{*}{0.352} & 28.82 & 18.94 & 36.87 \\
\hline & & Spring & 36 & -0.42 & 0.060 & -0.54 & -0.30 & & 34.30 & 25.92 & 41.73 \\
\hline & \multirow[t]{2}{*}{ PROT } & Winter & 41 & -0.54 & 0.069 & -0.67 & -0.40 & \multirow[t]{2}{*}{0.022} & 41.73 & 32.97 & 48.83 \\
\hline & & Spring & 28 & -0.77 & 0.075 & -0.92 & -0.62 & & 53.70 & 46.21 & 60.15 \\
\hline & \multirow[t]{2}{*}{ TEBU+PROT } & Winter & 40 & -0.59 & 0.072 & -0.73 & -0.45 & \multirow[t]{2}{*}{0.013} & 44.57 & 36.24 & 51.81 \\
\hline & & Spring & 33 & -0.85 & 0.075 & -1.00 & -0.71 & & 57.26 & 50.84 & 63.21 \\
\hline & \multirow[t]{2}{*}{ METC } & Winter & 32 & -0.48 & 0.070 & -0.62 & -0.34 & \multirow[t]{2}{*}{$<0.001$} & 38.12 & 28.82 & 46.21 \\
\hline & & Spring & 39 & -0.87 & 0.070 & -1.00 & -0.73 & & 58.10 & 51.81 & 63.21 \\
\hline \multirow[t]{10}{*}{ DON } & \multirow[t]{2}{*}{ TEBU } & Winter & 62 & -0.18 & 0.037 & -0.25 & -0.11 & \multirow[t]{2}{*}{0.002} & 16.47 & 10.42 & 22.12 \\
\hline & & Spring & 42 & -0.36 & 0.043 & -0.44 & -0.27 & & 30.23 & 23.66 & 35.60 \\
\hline & \multirow[t]{2}{*}{ PROP } & Winter & 21 & -0.05 & 0.040 & -0.13 & 0.03 & \multirow[t]{2}{*}{0.002} & 4.88 & -3.05 & 12.19 \\
\hline & & Spring & 24 & -0.24 & 0.042 & -0.32 & -0.15 & & 21.34 & 13.93 & 27.39 \\
\hline & \multirow[t]{2}{*}{ PROT } & Winter & 38 & -0.50 & 0.063 & -0.63 & -0.38 & \multirow[t]{2}{*}{0.214} & 39.35 & 31.61 & 46.74 \\
\hline & & Spring & 22 & -0.63 & 0.079 & -0.78 & -0.47 & & 46.74 & 37.50 & 54.16 \\
\hline & \multirow[t]{2}{*}{ TEBU+PROT } & Winter & 35 & -0.47 & 0.063 & -0.60 & -0.35 & \multirow[t]{2}{*}{0.079} & 37.50 & 29.53 & 45.12 \\
\hline & & Spring & 21 & -0.65 & 0.078 & -0.80 & -0.50 & & 47.80 & 39.35 & 55.07 \\
\hline & \multirow[t]{2}{*}{ METC } & Winter & 26 & -0.47 & 0.062 & -0.59 & -0.35 & \multirow[t]{2}{*}{0.005} & 37.50 & 29.53 & 44.57 \\
\hline & & Spring & 24 & -0.74 & 0.073 & -0.88 & -0.60 & & 52.29 & 45.12 & 58.52 \\
\hline
\end{tabular}

${ }^{a}$ IND $=$ Fusarium head blight index (mean proportion of diseased spikelets per spike) and DON = deoxynivanenol content of harvested grain (ppm).

b Active ingredients TEBU $=$ tebuconazole, $\mathrm{PROP}=$ propiconazole, $\mathrm{PROT}=$ prothioconazole, and METC $=$ metconazole

c Data obtained from winter wheat and spring wheat studies.

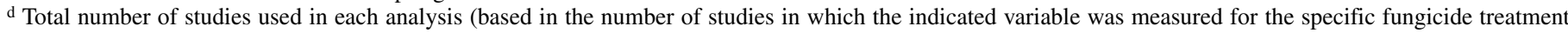
and the control).

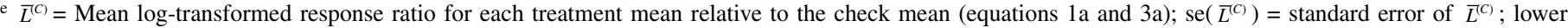
$\left(C I_{L}\right)$ and upper $\left(C I_{U}\right)$ limits of the $95 \%$ confidence interval around $\bar{L}^{(C)}$; and $Z$ (standard normal) statistic from the meta-analysis. $P=$ probability value (significance level).

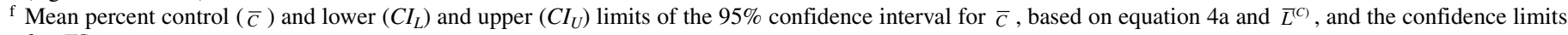
for $\bar{L}^{(C)}$. 
conazole+prothioconazole relative to tebuconazole was consistent across wheat types. For DON, the effect of wheat type on the log response ratio relative to tebuconazole was not significant $(P>$ 0.2 ) for any of the fungicides tested (Table 4).

Effects of mean disease and DON levels in the untreated check. In general, index and DON levels in the check plots had little or no influence on the efficacy of the fungicides, as measured by $\bar{L}^{(C)}$ and $\bar{L}^{T)}$ (and the corresponding $\bar{C}$ and $\bar{T}$ ). For all fungicides, $\bar{C}$ and $\bar{T}$ for both index and DON were most variable in the lowest index $\left(\bar{X}_{I N D} \leq 2 \%\right)$ and DON $\left(\bar{X}_{D O N}<1 \mathrm{ppm}\right)$ categories (Fig. 2), based on the width of the confidence intervals. Although the mean $\bar{C}$ values tended to be lower for the low disease or DON category compared with the other categories (Fig. $2 \mathrm{~A}$ and $\mathrm{C}$ ), the precision of the estimated means in that category was very low, precluding any significant result. For each fungicide treatment, $\bar{C}$ values were very similar between studies with $\bar{X}_{I N D}$ between 2 and $15 \%$ and $\bar{X}_{I N D} \geq 15 \%$, and between studies with $\bar{X}_{D O N}$ between 1 and $10 \mathrm{ppm}$ and $\bar{X}_{D O N} \geq 10 \mathrm{ppm}$. $\bar{T}$ also tended to be very similar among the upper two index and DON categories, with a slight tendency for $\bar{T}$ based on index to increase from the middle to upper category with prothioconazole and tebuconazole+prothioconazole treatments (Fig. 2B).

For either index or DON, the slopes for relationships between $\log$ response ratio for individual studies, $L_{i}^{(C)}$, and the $\log$ of the mean in the check for those studies, $Y_{i, \text { Check }}$, as described in equation 6, were not significantly different from zero for most situations (Table 5). This indicates that there was no overall evidence showing the influence of mean disease or DON levels on the efficacy of most of the fungicides (when efficacy is determined, as here, in terms of relative decrease in index or DON). This is consistent with Figure 2. The only exceptions were for the relationships between log-transformed $\bar{X}_{D O N}$ and $L_{i}^{(C)}$ for metconazole, and between log-transformed $\bar{X}_{I N D}$ and $L_{i}^{(C)}$ for prothioconazole. In both cases, the slope was positive and significantly different from zero (Table 5), suggesting that efficacy of metconazole and prothioconazole increased with increasing DON and index levels, respectively.
Effect of year. Year of study did not have significant effects on either $L^{(C)}$ or $L^{(T)}(P>0.2)$, for either index or DON, based on chi-square tests. This indicates that there was no evidence of a general increase or decrease in fungicide efficacy, for either index or DON, throughout the 11 years of this investigation.

Probability of lower disease or toxin than in the unsprayed treatment. The estimated probability that mean index or DON for a fungicide treatment in a randomly selected new study (done the same way as the studies in this investigation) was lower than the mean for the untreated plots $\left(p_{+}^{(C)}\right.$; i.e., probability of $C>0 \%$ ) was between 0.79 and 0.95 for the combined data set, 0.87 and 0.99 for spring wheat studies, and 0.64 and 0.92 for winter wheat studies (Table 6). For any given fungicide treatment, $p_{+}^{(C)}$ was higher for spring than for winter wheat. The lowest $p_{+}^{(C)}$ values corresponded to the propiconazole treatment, which had the lowest $\bar{L}^{(C)}$ and $\bar{C}$ values (Table 1 ). The $p_{+}^{(C)}$ values confirm that all the tested fungicides lower disease and toxin levels relative to not spraying, and that propiconazole was the least effective treatment.

The estimated probabilities of a fungicide treatment in a new study having $C>25$ and $50 \%$ ( $p_{25}^{(C)}$ and $p_{50}^{(C)}$, respectively) were all lower than the $p_{+}^{(C)}$ values, by definition (Table 6). $p_{25}^{(C)}$ and $p_{50}^{(C)}$ were higher for spring wheat than for winter wheat studies for all fungicides, for both index and DON (Table 6). In most cases, these probabilities were higher for index than for DON, and sometimes much higher, indicating the lower efficacy of the fungicide treatments for DON reduction than for disease reduction. For instance, with the tebuconazole treatment and spring wheat, $p_{50}^{(C)}$ was 0.40 for index and only 0.05 for DON control; with winter wheat and the same fungicide, $p_{50}^{(C)}$ was 0.17 for index and 0.01 for DON control. For spring wheat studies, metconazole had the highest $p_{25}^{(C)}$ and $p_{50}^{(C)}$ values for both index $(0.92$ and 0.67 ) and DON (0.91 and 0.56), followed by tebuconazole+prothioconazole and prothioconazole. For winter wheat studies, tebuconazole+prothioconazole had the highest $p_{25}^{(C)}$ and $p_{50}^{(C)}$ values for index $(0.75$ and 0.42$)$, followed by prothioconazole (0.72 and 0.36$)$ and metconazole (0.68 and 0.31$)$,

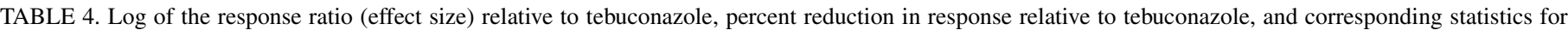

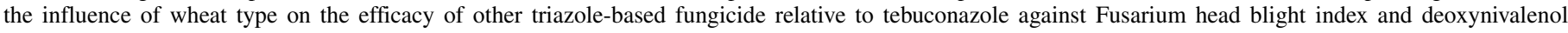
accumulation in wheat

\begin{tabular}{|c|c|c|c|c|c|c|c|c|c|c|c|}
\hline \multirow[b]{2}{*}{ Response $^{a}$} & \multirow[b]{2}{*}{ Fungicide $^{b}$} & \multirow[b]{2}{*}{ Type $^{\mathrm{c}}$} & \multirow[b]{2}{*}{$K^{\mathrm{d}}$} & \multicolumn{5}{|c|}{ Effect size ${ }^{e}$} & \multicolumn{3}{|c|}{ Percent relative of TEBU ${ }^{f}$} \\
\hline & & & & $\bar{L}^{(T)}$ & $\operatorname{se}\left(\bar{L}^{(T)}\right)$ & $C I_{L}$ & $C I_{U}$ & $P$ & $\bar{T}$ & $C I_{L}$ & $C I_{U}$ \\
\hline \multirow[t]{8}{*}{ IND } & \multirow[t]{2}{*}{ PROP } & Winter & 27 & 0.05 & 0.047 & -0.04 & 0.14 & \multirow[t]{2}{*}{0.032} & -5.13 & -15.03 & 3.92 \\
\hline & & Spring & 35 & 0.19 & 0.045 & 0.10 & 0.28 & & -20.92 & -32.31 & -10.52 \\
\hline & \multirow[t]{2}{*}{ PROT } & Winter & 41 & -0.15 & 0.048 & -0.25 & -0.05 & \multirow[t]{2}{*}{0.879} & 13.93 & 4.88 & 22.12 \\
\hline & & Spring & 28 & -0.16 & 0.062 & -0.28 & -0.04 & & 14.79 & 3.92 & 24.42 \\
\hline & \multirow[t]{2}{*}{ TEBU+PROT } & Winter & 40 & -0.21 & 0.046 & -0.30 & -0.12 & \multirow[t]{2}{*}{0.603} & 18.94 & 11.31 & 25.92 \\
\hline & & Spring & 33 & -0.24 & 0.056 & -0.35 & -0.13 & & 21.34 & 12.19 & 29.53 \\
\hline & \multirow[t]{2}{*}{ METC } & Winter & 32 & -0.09 & 0.053 & -0.20 & 0.01 & \multirow[t]{2}{*}{0.033} & 8.61 & -1.01 & 18.13 \\
\hline & & Spring & 39 & -0.26 & 0.056 & -0.37 & -0.15 & & 22.89 & 13.93 & 30.93 \\
\hline \multirow[t]{8}{*}{ DON } & \multirow[t]{2}{*}{ PROP } & Winter & 21 & 0.13 & 0.043 & 0.05 & 0.21 & \multirow[t]{2}{*}{0.901} & -13.88 & -23.37 & -5.13 \\
\hline & & Spring & 24 & 0.12 & 0.046 & 0.03 & 0.21 & & -12.75 & -23.37 & -3.05 \\
\hline & \multirow[t]{2}{*}{ PROT } & Winter & 38 & -0.32 & 0.048 & -0.41 & -0.23 & \multirow[t]{2}{*}{0.510} & 27.39 & 20.55 & 33.63 \\
\hline & & Spring & 22 & -0.27 & 0.063 & -0.39 & -0.15 & & 23.66 & 13.93 & 32.29 \\
\hline & \multirow[t]{2}{*}{ TEBU+PROT } & Winter & 34 & -0.29 & 0.049 & -0.39 & -0.19 & \multirow[t]{2}{*}{0.988} & 25.17 & 17.30 & 32.29 \\
\hline & & Spring & 21 & -0.29 & 0.063 & -0.41 & -0.16 & & 25.17 & 14.79 & 33.63 \\
\hline & \multirow[t]{2}{*}{ METC } & Winter & 24 & -0.29 & 0.046 & -0.38 & -0.20 & \multirow[t]{2}{*}{0.205} & 25.17 & 18.13 & 31.61 \\
\hline & & Spring & 26 & -0.38 & 0.055 & -0.49 & -0.27 & & 31.61 & 23.66 & 38.74 \\
\hline
\end{tabular}

${ }^{a}$ IND = Fusarium head blight index (mean proportion of diseased spikelets per spike) and DON = deoxynivalenol content of harvested grain (ppm).

b Active ingredients TEBU $=$ tebuconazole, $\mathrm{PROP}=$ propiconazole, $\mathrm{PROT}=$ prothioconazole, and $\mathrm{METC}=$ metconazole .

${ }^{c}$ Data obtained from winter wheat and spring wheat studies.

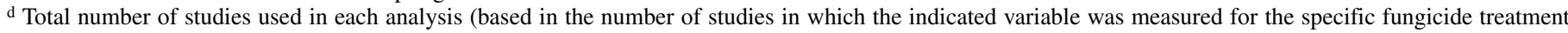
and tebuconazole).

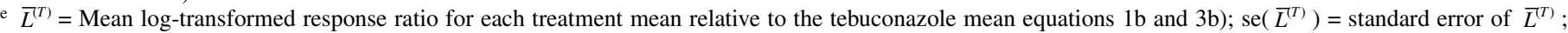
lower $\left(C I_{L}\right)$ and upper $\left(C I_{U}\right)$ limits of the $95 \%$ confidence interval around $\bar{L}^{T)}$; and $Z$ (standard normal) statistic from the meta-analysis of the effect of fungicide treatments, relative to tebuconazole, on IND and DON. $P=$ probability value (significance level).

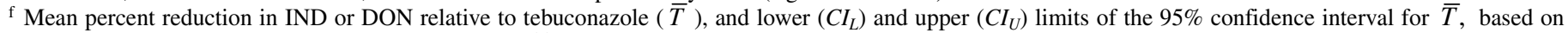
equation $4 \mathrm{~b}$ and $\bar{L}^{(T)}$, and the confidence limits for $\bar{L}^{(T)}$. 
whereas for DON, prothioconazole, tebuconazole+prothioconazole, and metconazole had very similar $p_{25}^{(C)}$ values $(0.71,0.70$ and 0.71$)$ and comparable $p_{50}^{(C)}$ values $(0.31,0.27$, and 0.26$)$. For all treatments, with one exception (metconazole with spring wheat, $\left.p_{50}^{(C)}=0.56\right)$, the probability of achieving over $50 \%(C>$ $50 \%$ ) control of DON in a study was less than half. For the propiconazole treatment and DON, $p_{50}^{(C)}$ was less than 0.01 for winter and spring wheat, and for the tebuconazole treatment and $\mathrm{DON}, p_{50}^{(C)}$ was less than 0.05 , indicating that there was very little chance for percent control to be $50 \%$ or better with these treatments. In contrast, $p_{50}^{(C)}$ for disease index was greater than half for three of the fungicide treatments with spring wheat (Table 6).

Probability of lower disease or DON than in the tebuconazole treatment. When considering the probability of one of the tested fungicides having greater efficacy $\left(p_{+}^{(T)}\right)$ than tebuconazole (i.e., $T>0 \%$ ) in a randomly selected new study, all products, with the exception of propiconazole, had $p_{+}^{(T)}$ values greater than 0.75 for index, and greater than 0.90 for DON (Table 6). Thus, all fungicides except propiconazole had greater efficacy than tebuconazole. The $p_{+}^{(T)}$ values were similar between spring and winter wheat studies for both index and DON for all tested fungicides, except for metconazole and propiconazole with index as the response (Table 6). For metconazole, $p_{+}^{(T)}$ was higher for spring wheat study (0.91) than for winter study (0.68) with the index response.

In the case of a tested fungicide resulting in greater than $25 \%$ improvement in efficacy over tebuconazole $(T>25 \%)$, almost all products had $p_{25}^{(T)}$ values greater than 0.25 for index, and greater than 0.50 for DON, for both winter and spring wheat. The only exceptions were for propiconazole with both wheat types $\left(p_{25}^{(T)}<\right.$ $0.01)$ and metconazole for index with winter wheat $\left(p_{25}^{(T)}=0.16\right)$. For spring wheat, metconazole had the greatest probability of resulting in greater than $25 \%$ improvement in efficacy over tebuconazole for both index $\left(p_{25}^{(T)}=0.44\right)$ and DON $\left(p_{25}^{(T)}=0.72\right)$, whereas for winter wheat, tebuconazole+prothioconazole and prothioconazole, respectively, had the greatest probabilities of greater than $25 \%$ improvement over tebuconazole for index $\left(p_{25}^{(T)}=0.32\right)$ and DON $\left(p_{25}^{(T)}=0.57\right)$ (Table 6).

The probability that a treatment in a randomly selected study had $50 \%$ or greater reduction of index or DON relative to the tebuconazole treatment $\left(p_{50}^{(T)}\right)$ was under 0.03 for all fungicides (for both index and DON), and results are not shown (L. V. Madden, unpublished data).

\section{DISCUSSION}

The reemergence of Fusarium head blight in the 1990s led to concerted efforts by wheat growers, researchers, and agribusiness leaders to find effective fungicides to minimize yield and quality losses due to this disease. Through the USWBSI, UFTs were conducted to provide the basis for evaluating fungicides for efficacy against Fusarium head blight and DON in wheat. The central goal of the UFTs was to identify products with the greatest and most consistent efficacy across wheat classes, years, locations, cropping system, and weather conditions. Over the last 10 to 12 years, several fungicides have been evaluated, with results ranging from no detectable effects to substantial reduction in both Fusarium head blight and DON $(18,40)$. In general, fungicides
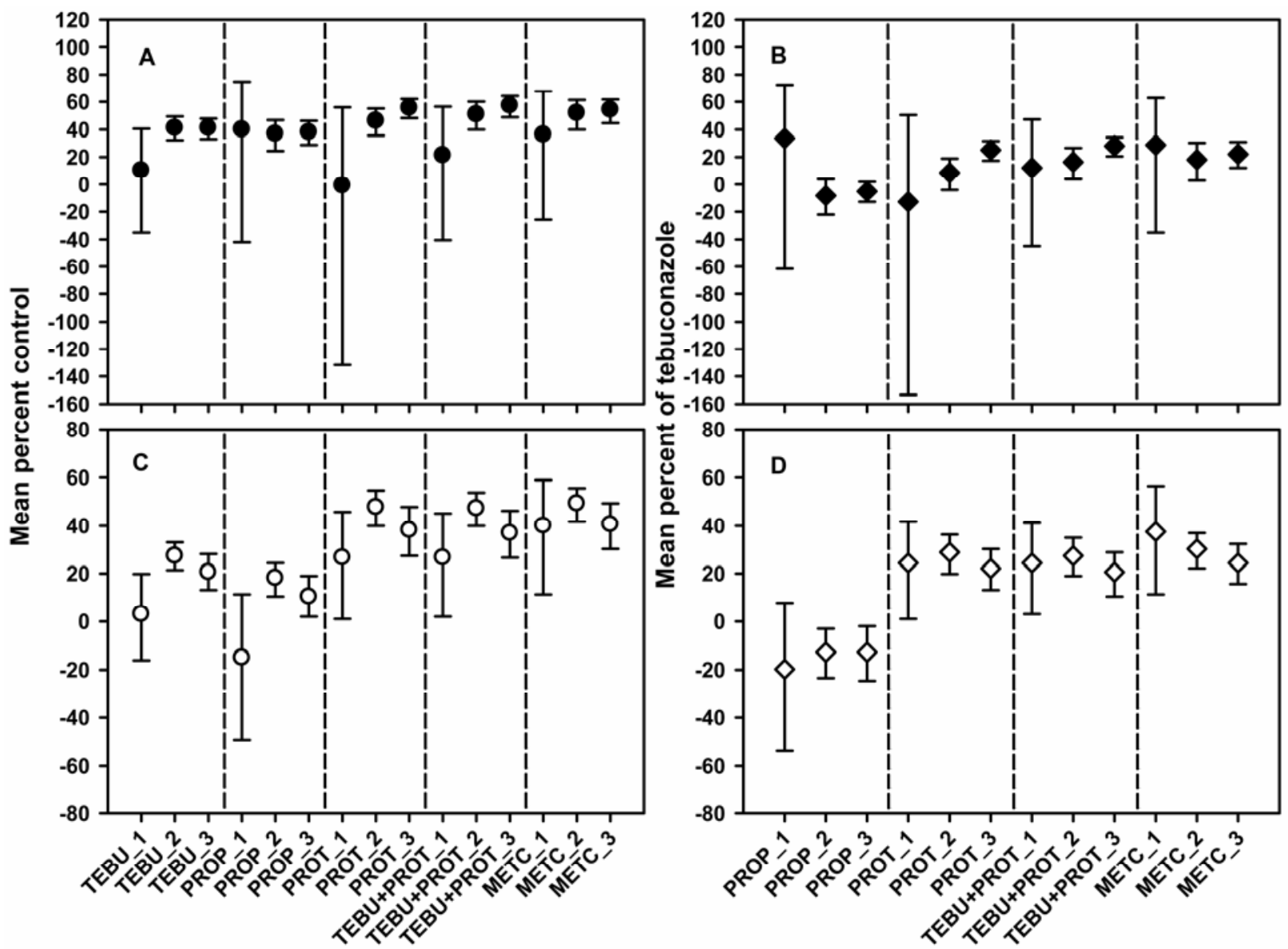

Fig. 2. Effects of tebuconazole (TEBU), propiconazole (PROP), prothioconazole (PROT), a mixture of tebuconazole and prothioconazole (TEBU+PROT), and metconazole (METC) on mean percent control relative to the untreated check of A, Fusarium head blight index (IND = mean percentage of diseased spikelets per spike), and $\mathbf{C}$, deoxynivalenol (DON) content of harvested wheat grain (parts per million), and mean percent reduction relative to the tebuconazole treatment of $\mathbf{B}$, IND, and D, DON. Results shown for different levels of IND (1, mean index $\leq 2 \% ; 2$, mean index between 2 and $15 \%$; and 3, mean index $\geq 15 \%)$ and DON (1, mean DON $<1 \mathrm{ppm} ; 2$, mean $\geq 1$ and $<10 \mathrm{ppm}$; and 3, mean DON $\geq 10 \mathrm{ppm}$ ) in the untreated check. 
with triazole chemistry have been the most effective, providing the most consistent results in terms of percent reduction in disease and DON $(11,17,19,20,35-37)$ relative to the untreated check. However, even among the triazoles or for a given triazole-based product, results vary from one individual study to another $(9,17$, $23,33,43,45,57)$. Due to the high variability and uncertainties as to the conditions under which fungicide applications would be effective and economically rational, routine fungicide recommendation for Fusarium head blight and DON control in wheat has received mixed reviews from both researchers and wheat producers.

TABLE 5. Estimated slope and corresponding statistics from a multivariate meta-analysis of the influence of $\log$ of mean disease and deoxynivalenol (DON) levels per study $\left(\ln \left(\bar{X}_{i, \text { Check }}\right)\right)$ on the $\log$ response ratio $\left(L_{i}^{(C)}\right)$ for effects of triazole-based fungicide on Fusarium head blight index and DON accumulation in wheat ${ }^{\mathrm{a}}$

\begin{tabular}{llrccc}
\hline Predictor $^{\mathrm{b}}$ & Fungicide $^{\mathrm{c}}$ & Slope & SE & $Z$ value & $P$ \\
\hline IND & TEBU & 0.007 & 0.036 & 0.19 & 0.848 \\
& PROP & 0.034 & 0.046 & 0.75 & 0.453 \\
& PROT & 0.119 & 0.055 & 2.17 & 0.031 \\
& TEBU+PROT & 0.038 & 0.056 & 0.67 & 0.503 \\
& METC & -0.004 & 0.062 & -0.06 & 0.952 \\
DON & TEBU & 0.007 & 0.025 & 0.26 & 0.793 \\
& PROP & -0.005 & 0.034 & -0.15 & 0.885 \\
& PROT & -0.006 & 0.043 & -0.15 & 0.884 \\
& TEBU+PROT & -0.005 & 0.038 & -0.14 & 0.890 \\
& METC & 0.149 & 0.009 & 15.92 & $<0.001$ \\
\hline
\end{tabular}

${ }^{a}$ Equations 6 and 7.

${ }^{\mathrm{b}}$ IND = Fusarium head blight index (mean proportion of diseased spikelets per spike) in the untreated check used as a continuous predictor of the effect of fungicides on disease and DON = deoxynivalenol content of harvested grain (ppm) in the untreated check used as a continuous predictor of the effect of fungicides on DON Log-transformed values were used as predictors in the meta-analysis to determine the influence of disease and DON levels on fungicide efficacy (quantified by way of $\log$ response ratios).

c Active ingredients TEBU $=$ tebuconazole, PROP $=$ propiconazole, PROT $=$ prothioconazole, and METC $=$ metconazole .
Using the results from UFTs, a multivariate random-effects meta-analytic approach was utilized to facilitate evaluation of the overall efficacy and consistency of tebuconazole, propiconazole, metconazole, prothioconazole, and tebuconazole+prothioconazole for Fusarium head blight control and DON reduction in wheat. Arends et al. (2) and Riley et al. (55) describe many of the advantages of multivariate over univariate methods in meta-analysis. One major advantage of relevance for our investigation is that all the response variables (i.e., treatment means) can be considered simultaneously, allowing for the utilization of estimated betweenstudy variances and correlations among responses in the (i) calculation of effect sizes (e.g., mean $\log$ ratios) and their confidence intervals; and (ii) assessment of the effect of selected responses (e.g., check mean) and moderator variables on the effect sizes. Multivariate analysis can be used whether or not all treatments are present in all individual studies; in fact, in terms of precise and accurate estimation of mean effect sizes, the multivariate approach shows its greatest superiority to the univariate approach when studies are incomplete (consisting of less than all the treatments of interest) $(31,55,61)$.

Several results are clear from the multivariate meta-analysis. All the tested fungicides reduced disease index in the field and DON concentration in harvested grain, although the degree of control for DON was less than for disease index. Overall, mean percent control $(\bar{C})$ ranged from 32 to $52 \%$ for index, and from 12 to $45 \%$ for DON. Effect sizes for tebuconazole were very similar to, but not quite the same as, that found in Paul et al. (45). The difference occurs because in the multivariate analysis observable results from all treatments and studies contributed to the estimation of all mean effect sizes $(55,61)$ for each treatment, even though studies generally did not consist of all treatments. This is a consequence of the fact that the mean effect sizes depend, in part, on the between-study correlations (covariances) of responses for the different treatments (55). This is similar to how data from all blocks are utilized in an incomplete block design, where only a portion of the treatments occur in each block

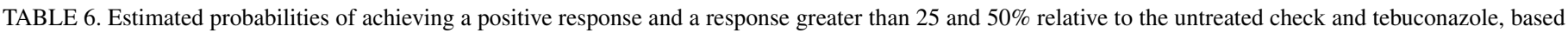

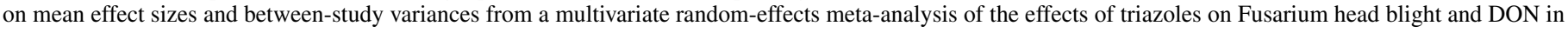
wheat

\begin{tabular}{|c|c|c|c|c|c|c|c|}
\hline \multirow[b]{3}{*}{ Response $^{\mathrm{a}}$} & \multirow[b]{3}{*}{ Fungicide $^{\mathrm{b}}$} & \multirow[b]{3}{*}{ Type } & \multicolumn{5}{|c|}{ Probability of a response ${ }^{c}$} \\
\hline & & & \multicolumn{3}{|c|}{ Relative to the check } & \multicolumn{2}{|c|}{ Relative to TEBU } \\
\hline & & & $p_{+}^{(C)}$ & $p_{25}^{(C)}$ & $p_{50}^{(C)}$ & $p_{+}^{(T)}$ & $p_{25}^{(T)}$ \\
\hline \multirow[t]{10}{*}{ IND } & \multirow[t]{2}{*}{ TEBU } & Spring & 0.97 & 0.84 & 0.40 & $\ldots$ & $\ldots$ \\
\hline & & Winter & 0.89 & 0.62 & 0.17 & $\ldots$ & $\ldots$ \\
\hline & \multirow[t]{2}{*}{ PROP } & Spring & 0.87 & 0.64 & 0.23 & 0.09 & $<0.01$ \\
\hline & & Winter & 0.82 & 0.55 & 0.17 & 0.36 & 0.01 \\
\hline & \multirow[t]{2}{*}{ PROT } & Spring & 0.96 & 0.87 & 0.58 & 0.77 & 0.28 \\
\hline & & Winter & 0.89 & 0.72 & 0.36 & 0.76 & 0.26 \\
\hline & \multirow[t]{2}{*}{ TEBU+PROT } & Spring & 0.97 & 0.89 & 0.64 & 0.91 & 0.40 \\
\hline & & Winter & 0.90 & 0.75 & 0.42 & 0.88 & 0.32 \\
\hline & \multirow[t]{2}{*}{ METC } & Spring & 0.98 & 0.92 & 0.67 & 0.91 & 0.44 \\
\hline & & Winter & 0.88 & 0.68 & 0.31 & 0.68 & 0.16 \\
\hline \multirow[t]{10}{*}{ DON } & \multirow[t]{2}{*}{ TEBU } & Spring & 0.96 & 0.64 & 0.05 & $\ldots$ & $\ldots$ \\
\hline & & Winter & 0.81 & 0.30 & 0.01 & $\ldots$ & $\ldots$ \\
\hline & \multirow[t]{2}{*}{ PROP } & Spring & 0.96 & 0.35 & $<0.01$ & 0.21 & $<0.01$ \\
\hline & & Winter & 0.64 & 0.04 & $<0.01$ & 0.20 & $<0.01$ \\
\hline & \multirow[t]{2}{*}{ PROT } & Spring & 0.95 & 0.82 & 0.44 & 0.92 & 0.46 \\
\hline & & Winter & 0.91 & 0.71 & 0.31 & 0.95 & 0.57 \\
\hline & \multirow[t]{2}{*}{ TEBU+PROT } & Spring & 0.97 & 0.85 & 0.45 & 0.93 & 0.50 \\
\hline & & Winter & 0.91 & 0.70 & 0.27 & 0.93 & 0.50 \\
\hline & \multirow[t]{2}{*}{ METC } & Spring & 0.99 & 0.91 & 0.56 & 0.99 & 0.72 \\
\hline & & Winter & 0.92 & 0.71 & 0.26 & 0.97 & 0.50 \\
\hline
\end{tabular}

${ }^{a}$ IND = Fusarium head blight index (mean proportion of diseased spikelets per spike) and DON = deoxynivalenol content of harvested grain (ppm).

b Active ingredients TEBU $=$ tebuconazole, $\mathrm{PROP}=$ propiconazole, $\mathrm{PROT}=$ prothioconazole, and METC $=$ metconazole.

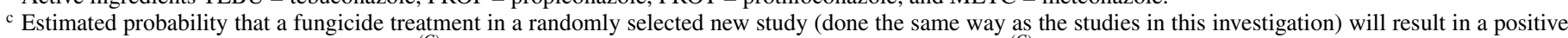
control relative to the untreated check $\left(p_{+}^{(C)}\right)$, a percent control of at least $50 \%$ relative to the check $\left(p_{50}^{(C)}\right)$, a percent control of at least $25 \%$ relative to the check $\left(p_{25}^{(C)}\right)$, control that is better than that achieved with tebuconazole $\left(p_{+}^{(T)}\right)$, and control that is at least $25 \%$ better than that achieved with tebuconazole. $\ldots=$ not applicable. 
(by definition). Tebuconazole+prothioconazole, as a tank mix or premix, had the numerically highest mean percent control for disease index $(52 \%)$, although prothioconazole and metconazole treatments showed comparable results. These three products also showed similar efficacy against DON, with metconazole resulting in the numerically highest mean percent control of $45 \%$, followed closely by prothioconazole and tebuconazole+prothioconazole. All the tested fungicides had greater efficacy than tebuconazole (which had a $\bar{C}$ of $40 \%$ for index and $23 \%$ for DON), except for propiconazole. Relative to tebuconazole, prothioconazole, metconazole, and tebuconzole+prothioconzole reduced index a further 14 to $20 \%$ and DON a further 25 to $29 \%(\bar{T})$. In contrast, disease index and DON for the propiconazole treatment was about $13 \%$ higher than for tebuconazole.

Furthermore, all the fungicides had greater efficacy with spring wheat than with soft winter wheat; mean percent control for index was 12 to 20 percentage points higher with spring than with winter wheat, and from 7 to 16 points higher with DON. There was no effect of year of study on the effect sizes, and the effect sizes did not, in general, vary systematically with disease index or DON in the check. Regarding the latter result, it should be noted that when the response ratio, $R$, or its $\log$ transformation $(L)$ is fixed, the difference in mean disease or toxin between the treated and check plots increases as the disease or toxin in the check increases (in order to maintain a constant ratio or constant relative difference $[C]$ ). Although there tended to be lower $\bar{C}$ when disease index or DON in the check was very low, there was also much higher variability in effect sizes for this compared with the higher categories of index or DON. This low index/DON result is because of the uncertainty in estimating ratios when the denominator is close to 0 (15).

In addition to the estimation of mean effect sizes and their confidence intervals, the multivariate meta-analysis was of direct use in a quantitative risk analysis for disease index or DON $(12,51)$. Risk in this context is a probability that is a function of a mean and variance $(50,51)$. The risk in the current investigation was quantified through the estimated probability that the percent control (of disease or toxin) in a randomly selected study exceeded $0\left(p_{+}^{(C)}\right), 25\left(p_{25}^{(C)}\right)$, or $50 \%\left(p_{50}^{(C)}\right)$ for each of these treatments, as well as the probability that disease or toxin in a treatment was lower $\left(p_{+}^{(T)}\right)$, or more than $25 \%$ lower $\left(p_{25}^{(T)}\right)$, than in the tebuconazole treatment (59). These probabilities depend on both the mean effect sizes and the estimated between-study variances for the effect sizes. Although all fungicide treatments resulted in large $p_{+}^{(C)}$ values, indicating that they all can be expected (on average) to reduce Fusarium head blight and DON when applied (relative to not applying a fungicide), only the prothioconazole, metconazole, and tebuconazole+prothioconazole treatments resulted in reasonably large $p_{25}^{(C)}$ and $p_{50}^{(C)}$ values for both index and DON. All the probabilities were (considerably) larger for spring than winter wheat, and larger for disease index than for DON. Interestingly, based on $p_{25}^{(T)}$ values, compared with tebuconazole, these three treatments resulted in a greater improvement in control efficacy for DON than for disease index. This was due to the lower efficacy of tebuconazole for DON reduction than for disease control $\left(p_{50}^{(C)}\right)$.

Triazoles belong to a group of compounds called C14-demethylation inhibitors or sterol biosynthesis inhibitors and are of two main types, the 1,2,4-triazoles and the imidazoles (21). All fungicides evaluated in this study were 1,2,4-triazoles, with a common site-specific mode of action of disrupting sterol synthesis at a single site. Despite this similarity, however, these products showed considerable differences in efficacy, and for a given product, efficacy varied between spring and soft winter wheat trials. The observed differences in efficacy may have been partly due to inherent differences in chemical and physical formulation among the fungicides that are probably unrelated to their mode of action; inherent differences in sensitivity of local populations of the fungus to the fungicides; and possible interactions involving fungicide, environment, crop development, and fungal population. For instance, different triazoles have been shown to have significantly different effects on germination of ascospores (26) and radial mycelial growth (60) of Gibberella zeae. Differences in cultivar resistance and weather conditions during crop development between spring and soft winter wheat trials may have been responsible for regional differences in fungicide efficacy. Even though susceptible cultivars were planted in all UFTs, observations in North and South Dakota suggest that spring wheat cultivars were probably less susceptible than winter wheat cultivars (M. A. Draper, unpublished data; M. P. McMullen, unpublished data). Fungicide efficacy against Fusarium head blight, DON, and Fusarium-damaged kernels has been shown to be greater for resistant than for susceptible cultivars (38). Coupled with relatively less susceptible cultivars, generally warmer conditions during spring wheat growing seasons compared with winter wheat growing seasons may have enhanced fungicide efficacy (52). Moreover, due to cooler weather conditions, the grain-fill period is usually longer in winter wheat than in spring wheat (20). Hershman and Milus (20) suggested that longer grain-filling periods in winter wheat areas would require fungicides to protect spikes for a longer time and could potentially increase the prospect of late-season primary infection (colonization) and secondary infections occurring several days after application when fungicides are less effective (58).

For all of the fungicides evaluated in this investigation in both spring and winter wheat trials, efficacy was clearly higher for index than for DON. Fungicide effects against infection, colonization, and fungal biomass buildup, which are strongly associated with DON accumulation $(10,39)$, only last for a relatively short period of time. During the time between anthesis and harvest, infections $(6,49,54)$ could occur and DON concentration may increase in fungicide-treated plots. Conversely, certain postanthesis weather conditions, especially high rainfall, may cause DON content to decrease during the time between fungicide application and DON quantification (5). These additional sources of variation in DON accumulation, coupled with differential DON accumulation among cultivars $(45,48,56)$, affect the final level of DON in harvested grain, potentially obscuring estimates of fungicide efficacy against DON. Changes in DON content may occur in the absence of visual symptom or without detectable increases in the level of visual symptoms (27).

In conclusion, although all of the tested triazoles provided significant reduction in Fusarium head blight and DON, metconazole and prothioconazole (both alone and in combination with tebuconazole) were consistently more effective than tebuconazole and especially propiconazole. For all tested fungicides, efficacy was greater in spring wheat trials than in soft winter wheat trials, suggesting that fungicide application will likely be more cost effective for spring than winter wheat. However, even in winter wheat, the use of prothioconazole, recently registered as Proline 480 SC, may be economical for managing Fusarium head blight and DON when conditions are favorable for disease development $(7,8)$. It is clear from the mean levels of DON and disease index in treated plots in individual studies (Fig. 1), the mean percent control found in the meta-analysis, and the associated risk $\left(p_{+}^{(C)}\right.$, $p_{25}^{(C)}$, and $p_{50}^{(C)}$ ) values, that even the best fungicides will not be sufficient alone to reduce DON levels to satisfactory levels under conditions highly conducive for disease development-high inoculum density, susceptible cultivars, and prolonged wet, humid weather. These were the conditions simulated in the UFTs, through artificial inoculation, mist irrigation around anthesis, and planting of susceptible cultivars. The highest mean percent control for DON was around 52\% in spring wheat and 40\% in winter wheat, and most treatments had lower percents for control. Although there was no compelling evidence that the percent control changed systematically with disease or DON levels, the 
mean DON level could still be quite large (and certainly above 2 to $5 \mathrm{ppm}$ ) with a $50 \%$ reduction, if the level of DON in the check was high to start with. Therefore, fungicides should be used along with other management practices such as tillage, crop rotation, and resistant cultivars to achieve greater levels of disease and DON reduction. Recent evaluations of integrated approaches for managing Fusarium head blight and DON showed that percent control increased substantially more when fungicide application was combined with residue management and cultivar resistance $(3,32,47)$ than when any of these strategies were used alone.

\section{ACKNOWLEDGMENTS}

Salaries and research support were provided by state and federal funds to the Ohio Agricultural Research and Development Center (OARDC). This investigation is based upon work supported, in part, by the U.S. Department of Agriculture (Agreement no. 59-0790-4-112). This is a cooperative project with the U.S. Wheat \& Barley Scab Initiative (USWBSI). Any opinions, findings, conclusions, or recommendations expressed in this publication are those of the authors and do not necessarily reflect the view of the U.S. Department of Agriculture.

\section{LITERATURE CITED}

1. Arends, L. R., Hoes, A. W., Lubsen, J., Grobbee, D. E., and Stijnen, T. 2000. Baseline risk as predictor of treatment benefit: Three clinical metare-analyses. Stat. Med. 19:3497-3518.

2. Arends, L. R., Voko, Z., and Stijnen, T. 2003. Combining multiple outcome measures in a meta-analysis: An application. Stat. Med. 22:13351353.

3. Bayer, M., Klix, M. B., Klink, H., and Verreet, J. A. 2006. Quantifying the effects of previous crop, tillage, cultivar and triazole fungicides on the deoxynivalenol content of wheat grain-A review. J. Plant Dis. Prot. 113:241-246.

4. Boyacioglu, D., Hettiarachchy, N. S., and Stack, R. W. 1992. Effect of three systemic fungicides on deoxynivalenol (vomitoxin) production by Fusarium graminearum in wheat. Can. J. Plant Sci. 72:93-101.

5. Cutter, M. D., Miller-Garvin, J. E., and Dill-Macky, R. 2007. Effect of extended irrigation on host resistance and deoxynivalenol accumulation in Fusarium-infected wheat. Plant Dis. 91:1464-1472.

6. Del Ponte, E. M., Fernandes, J. M. C., and Bergstrom, G. C. 2003. Fusarium head blight and deoxynivalenol accumulation in wheat inoculated at developmental stages from flowering through grain maturation. Pages 129-132 in: Proc. 2003 National Fusarium Head Blight Forum. Michigan State University, MI.

7. DeWolf, E. D., and Isard, S. A. 2007. Disease cycle approach to plant disease prediction. Annu. Rev. Phytopathol. 45:203-220.

8. DeWolf, E. D., Madden, L. V., and Lipps P. E. 2003. Risk assessment models for wheat Fusarium head blight epidemics based on within-season weather data. Phytopathology 93:428-435.

9. Draper, M. A., Rudd, J., Casper, H. H., Ruden, K. R., and Lammers, G. 2000. Performance of various fungicides for suppression of Fusarium head blight in South Dakota. Page 85-88 in: Proc. 2000 National Fusarium Head Blight Forum. Michigan State University, MI.

10. Edwards, S. G., Pirgozliev, S. R., Hare, M. C., and Jenkinson, P. 2001. Quantification of trichothecene-producing Fusarium Species in harvested grain by competitive PCR to determine efficacies of fungicides against Fusarium head blight of winter wheat. Appl. Environ. Microbiol. 67: 1575-1580.

11. El-Allaf, S. M., Lipps, P. E., Madden, L. V., and Johnston, A. 2001. Effect of foliar fungicide and biocontrol agents on Fusarium head blight development and control in Ohio. Pages 49-52 in: Proc. 2001 National Fusarium Head Blight Forum. Michigan State University, MI.

12. Eskridge, K. M., and Mumm, R. F. 1992. Choosing plant cultivars based on the probability of outperforming a check. Theor. Appl. Genet. 84:894900.

13. Gurevitch, J., and Hedges, L. V. 1993. Meta-analysis: Combining the results of independent experiments. Pages 378-425 in: Design and Analysis of Ecological Experiments. S. M. Scheiner and J. Gurevitch, eds. Chapman and Hall, London.

14. Hart, L. P., and Schabenberger, O. 1998. Variability of vomitoxin in truckloads of wheat in a wheat scab epidemic year. Plant Dis. 82:625-630.

15. Hedges, L. V., Gurevitch, J., and Curtis, P. S. 1999. The meta-analysis of response ratios in experimental ecology. Ecology 80:1150-1156.

16. Hedges, L. V., and Olkin, I. 1980. Vote-counting methods in research synthesis. Psychol. Bull. 88:359-369.
17. Hershman, D., and Draper, M. 2004. Analysis of 2004 uniform fungicide trials across locations and wheat classes. Pages 318-319 in: Proc. 2nd International Symposium on Fusarium Head Blight. Michigan State University, MI.

18. Hershman, D. E., Bachi, P. R., TeKrony, D. M., and VanSanford, D. A. 2001. Management of Fusarium head blight in wheat using selected biological control agents and foliar fungicides, 2001. Pages 59-63 in: Proc. 2001 National Fusarium Head Blight Forum. Michigan State University, MI.

19. Hershman, D. E., and Milus, E. A. 2002. Analysis of the 2002 uniform wheat fungicide and biocontrol trials across locations. Pages 82-87 in: Proc. of the 2002 National Fusarium Head Blight Forum. Michigan State University, MI.

20. Hershman, D. E., and Milus, E. A. 2003. Performance of Folicur in Fusarium head blight uniform fungicide trials, 1998-2003. Pages 81-82 in: Proc. 2003 National Fusarium Head Blight Forum. Michigan State University, MI.

21. Hewitt, H. G. 1998. Fungicides in Crop Protection. CAB International, New York.

22. Higgins, J. P. T., and Thompson, S. G. 2002. Quantifying heterogeneity in a meta-analysis. Stat. Med. 21:1539-1558.

23. Hollingsworth, C. R., and Motteberg, C. D. 2003. Uniform fungicide trials on FHB of wheat and barley in Minnesota. Pages 84-86 in: Proc. 2003 National Fusarium Head Blight Forum. Michigan State University, MI.

24. Homdork, S., Fehrmann, H., and Beck, R. 2000. Effects of field application of tebuconazole on yield, yield components and the mycotoxin content of Fusarium-infected wheat grain. J. Phytopathol. 148:1-6.

25. Hunter, J. E., and Schmidt, F. L. 2004. Methods of Meta-Analysis: Correcting Error and Bias in Research Findings. 2nd ed. Sage Publications Inc., Thousand Oaks, CA.

26. Klix, M. B., Verreet, J.-A., and Beyer, M. 2007. Comparison of the declining triazole sensitivity of Gibberella zeae and increased sensitivity achieved by advances in triazole fungicide development. Crop Prot. 26:683-690.

27. Lacey, J., Bateman, G. L., and Mirocha, C. J. 1999. Effects of infection time and moisture on development of ear blight and deoxynivalenol production by Fusarium spp. in wheat. Ann. Appl. Biol. 134:277-283.

28. Large, E. C. 1954. Growth stages in cereals. Plant Pathol. 3:128-129.

29. Lipsey, M. W., and Wilson, D. B. 2001. Practical Meta-Analysis. Sage Publications Inc., Thousand Oaks, CA.

30. Littell, R. C., Milliken, G. A., Stroup, W. W., Wolfinger, R. D., and Schabenberger, O. 2006. SAS for Mixed Models. SAS Institute, Cary, NC.

31. Lu, G., and Ades, A. E. 2004. Combination of direct and indirect evidence in mixed treatment comparisons. Stat. Med. 23:3105-3124.

32. McMullen, M. 2007. Experiences in reducing disease and DON through components of FHB management. Pages 102-103 in: Proc. 2007 Natl. Fusarium Head Blight Forum. Michigan State University, East Lansing.

33. McMullen, M., Halley, S., Pederson, J., Moos, J., and Jordahl, J. 2000. Effects of application parameters on control of Fusarium head blight with fungicides. Pages 94-97 in: Proc. of the 2000 National Fusarium Head Blight Forum. Michigan State University, MI.

34. McMullen, M., Lukach, J., McKay, K., and Schatz, B. 2004. Wheat uniform fungicide trials, ND, 2004. Pages 353-354 in: Proc. 2nd International Symposium on Fusarium Head Blight. Michigan State University, MI.

35. McMullen, M., Milus, G., and Prom, L. 1999. Uniform fungicide trials to identify products effective against Fusarium head blight in wheat. Pages 64-68 in: Proc. 1999 National Fusarium Head Blight Forum. Michigan State University, MI.

36. Mesterházy, Á., and Bartók, T. 1997. Effect of chemical control on FHB and toxin contamination of wheat. Cereal Res. Comm. 25:781-783.

37. Mesterházy, Á., and Bartók, T. 2001. Fungicide control of Fusarium head blight in wheat. Pages 70-74 in: Proc. 2001 National Fusarium Head Blight Forum. Michigan State University, MI.

38. Mesterházy, Á., Bartók, T., and Lamper, C. 2003. Influence of wheat cultivar, species of Fusarium, and isolate aggressiveness on the efficacy of fungicides for control of Fusarium head blight. Plant Dis. 87:11071115.

39. Miller, J. D., Young, J. C., and Sampson, D. R. 1985. Deoxynivalenol and Fusarium head blight resistance in spring cereals. Phytopathol. Z. 113:359-367.

40. Milus, E. A., Hershman, D., and McMullen, M. 2001. Analysis of the 2001 uniform fungicide and biocontrol trials across locations. Pages 7581 in: Proc. 2001 National Fusarium Head Blight Forum. Michigan State University, MI.

41. Molineros, J., DeWolf, E., Madden, L., Paul, P., and Lipps, P. 2005. Incorporation of host reaction and crop residue level into prediction models for Fusarium head blight. Pages 119-122 in: Proc. 2005 Natl. Fusarium Head Blight Forum. Michigan State University, East Lansing. 
42. Paul, P. A., El-Allaf, S. M., Lipps, P. E., and Madden, L. V. 2005. Relationships between incidence and severity of Fusarium head blight on winter wheat in Ohio. Phytopathology 95:1049-1060.

43. Paul, P. A., Hershman, D., Draper, M., and Madden, L. V. 2005. Effect of fungicides on FHB and DON in wheat-2005 uniform fungicide trials. Pages 225-229 in: Proc. 2005 Natl. Fusarium Head Blight Forum. Michigan State University, MI.

44. Paul, P. A., Lipps, P. E., and Madden, L. V. 2005. Relationship between visual estimates of Fusarium head blight intensity and deoxynivalenol accumulation in harvested wheat grain: A meta-analysis. Phytopathology 95:1225-1236.

45. Paul, P. A., Lipps, P. E., Hershman, D. E., McMullen, M. P., Draper, M. A., and Madden, L. V. 2007. A quantitative review of tebuconazole effect on Fusarium head blight and deoxynivalenol content in wheat. Phytopathology 97:211-220.

46. Paul, P. A., Lipps, P. E., and Madden, L. V. 2006. Meta-analysis of regression coefficients for the relationship between Fusarium head blight and deoxynivalenol content of wheat. Phytopathology 96:951-961.

47. Paul, P., Madden, L., McMullen, M., Hershman, D., Sweets, L., Wegulo, S., Bockus, W., Halley, S., and Ruden, K. 2007. An integrated approach to managing FHB and DON in wheat: Uniform trials 2007. Pages 117-122 in: Proc. 2007 Natl. Fusarium Head Blight Forum. Michigan State University, East Lansing.

48. Paul, P. A., Madden, L. V., Wegulo, S., Adhikari, T., Ali, S., and De Wolf, E. 2007. Influence of SRWW, HRSW, and HRWW varieties on the relationship between FHB and DON. Page 128 in: Proc. 2007 Natl. Fusarium Head Blight Forum. Michigan State University, East Lansing.

49. Paulitz, T. C. Fernando, W. G. D., and Seaman, W. L. 1997. Susceptibility of wheat heads at different growth stages when exposed to ascospores of Gibberella zeae. Pages 52-32 in: Proc. 1997 National Fusarium Head Blight Forum. Michigan State University, MI.

50. Piepho, H.-P. 1998. Methods for comparing the yield stability of cropping systems-A review. J. Agron. Crop Sci. 180:193-213.

51. Piepho, H.-P., and McCulloch, C. E. 2004. Transformations in mixed models: Application to risk analysis for a multivariate trial. J. Agric. Biol. Environ. Stat. 9:123-137.

52. Ramirez, M. L., Chulze, S., and Magan, N. 2004. Impact of environmental factors and fungicides on growth and deoxynivalenol production by Fusarium graminearum isolates from Argentinean wheat. Crop Prot. 23:117-125.

53. Raudenbush, S. W., Becker, B. J., and Kalaian, H. 1988. Modeling multivariate effect sizes. Psychol. Bull. 103:111-120.

54. Reis, E. M., Blum, M. M. C., and Casa, R. T. 1996. Controle quimico de Gibberella zeae em trigo, um problema de deposicao de fungicidas em anteras. Summa Phytopathol. 22:39-42.

55. Riley, R. D., Abrams, K. R., Lambert, P. C., Sutton, A. J., and Thompson, J. R. 2007. An evaluation of bivariate random-effects meta-analysis for the joint synthesis of two correlated outcomes. Stat. Med. 26:78-97.

56. Salgado, J. D., Broders, G., Madden, L., and Paul, P. 2007. Characterization of DON accumulation in SRWW cultivars with different levels of type II resistance to FHB. Page 137 in: Proc. 2007 Natl. Fusarium Head Blight Forum. Michigan State University, East Lansing.

57. Shaner, G. and Buechley, G. 2000. Control of Fusarium head blight of wheat with foliar fungicides. Pages 110-113 in: Proc. 2000 National Fusarium Head Blight Forum. Michigan State University, MI.

58. Suty, A., Mauler-Machnik, A., and Courbon, R. 1996. New findings on the epidemiology of Fusarium ear blight on wheat and its control with tebuconazole. Pages 511-516 in: Proc. The Brighton Crop Protection Conference: Pest and Diseases, Volume 2. Brighton, UK.

59. van Houwelingen, H. C., Arends, L. R., and Stijnen, T. 2002. Advanced methods in meta-analysis: Multivariate approach and meta-regression. Stat. Med. 21:589-624.

60. Wallhead, M., Madden, L., and Paul, P. 2007. Differential sensitivity to triazole-based fungicides among isolates of Fusarium graminearum. Page 141 in: Proc. 2007 Natl. Fusarium Head Blight Forum. Michigan State University, East Lansing.

61. Whitehead, A. 2002. Meta-Analysis of Controlled Clinical Trials. John Wiley and Sons, West Sussex, England. 